\title{
OPEN Kinetic studies and homology modeling of a dual-substrate linalool/nerolidol synthase from Plectranthus amboinicus
}

\author{
Nur Suhanawati Ashaari ${ }^{1}$, Mohd Hairul Ab. Rahim ${ }^{1,2}$, Suriana Sabri ${ }^{3,4}$, Kok Song Lai $^{5}$, \\ Adelene Ai-Lian Song ${ }^{4}$, Raha Abdul Rahim ${ }^{1}$ \& Janna Ong Abdullah ${ }^{1 凶}$
}

Linalool and nerolidol are terpene alcohols that occur naturally in many aromatic plants and are commonly used in food and cosmetic industries as flavors and fragrances. In plants, linalool and nerolidol are biosynthesized as a result of respective linalool synthase and nerolidol synthase, or a single linalool/nerolidol synthase. In our previous work, we have isolated a linalool/nerolidol synthase (designated as PamTps1) from a local herbal plant, Plectranthus amboinicus, and successfully demonstrated the production of linalool and nerolidol in an Escherichia coli system. In this work, the biochemical properties of PamTps1 were analyzed, and its 3D homology model with the docking positions of its substrates, geranyl pyrophosphate $\left(C_{10}\right)$ and farnesyl pyrophosphate $\left(C_{15}\right)$ in the active site were constructed. PamTps1 exhibited the highest enzymatic activity at an optimal pH and temperature of 6.5 and $30^{\circ} \mathrm{C}$, respectively, and in the presence of $20 \mathrm{mM}$ magnesium as a cofactor. The Michaelis-Menten constant $\left(K_{\mathrm{m}}\right)$ and catalytic efficiency $\left(k_{c a t} / K_{\mathrm{m}}\right)$ values of $16.72 \pm 1.32 \mu \mathrm{M}$ and $9.57 \times 10^{-3} \mu \mathrm{M}^{-1} \mathrm{~s}^{-1}$, respectively, showed that PamTps1 had a higher binding affinity and specificity for GPP instead of FPP as expected for a monoterpene synthase. The PamTps1 exhibits feature of a class I terpene synthase fold that made up of $\alpha$-helices architecture with $\mathrm{N}$-terminal domain and catalytic C-terminal domain. Nine aromatic residues (W268, Y272, Y299, F371, Y378, Y379, F447, Y517 and Y523) outlined the hydrophobic walls of the active site cavity, whilst residues from the $R R x_{8} W$ motif, RxR motif, $\mathrm{H}-\alpha 1$ and J-K loops formed the active site lid that shielded the highly reactive carbocationic intermediates from the solvents. The dual substrates use by PamTps1 was hypothesized to be possible due to the architecture and residues lining the catalytic site that can accommodate larger substrate (FPP) as demonstrated by the protein modelling and docking analysis. This model serves as a first glimpse into the structural insights of the PamTps1 catalytic active site as a multi-substrate linalool/ nerolidol synthase.

Terpenoids are structurally diverse and are the most abundant natural products among the myriad of compounds produced by plants, with biological roles ranging from growth and development to intracellular signaling and defense against predatory species ${ }^{1}$. Applications of these valuable compounds in the industries include as pharmaceuticals, flavors, fragrances and biofuels ${ }^{2}$. In higher plants, terpenoids are synthesized via either the cytosolic mevalonate (MVA) pathway or the plastidial methylerythritol phosphate (MEP) pathway, where the precursors are converted into structurally diverse terpenoids by the family of terpene synthases (TPSs). Sesquiterpene synthases responsible for sesquiterpenes $\left(C_{15}\right)$ production are localized in the cytosol, whereas monoterpene synthases that catalyze the production of monoterpenes $\left(\mathrm{C}_{10}\right)$ are present in the plastids. Monoterpene synthases (600-650 amino acids) are longer than sesquiterpene synthases (550-580 amino acids) due to their $\mathrm{N}$-terminal

\footnotetext{
${ }^{1}$ Department of Cell and Molecular Biology, Faculty of Biotechnology and Biomolecular Sciences, Universiti Putra Malaysia, 43400, UPM Serdang, Selangor, Malaysia. ${ }^{2}$ Department of Industrial Biotechnology, Faculty of Industrial Sciences and Technology, Universiti Malaysia Pahang, 26300 Gambang, Kuantan, Pahang, Malaysia. ${ }^{3}$ Enzyme and Microbial Technology Research Center, Faculty of Biotechnology and Biomolecular Sciences, Universiti Putra Malaysia, 43400, UPM Serdang, Selangor, Malaysia. ${ }^{4}$ Department of Microbiology, Faculty of Biotechnology and Biomolecular Sciences, Universiti Putra Malaysia, 43400, UPM Serdang, Selangor, Malaysia. ${ }^{5}$ Health Sciences Division, Abu Dhabi Women's College, Higher Colleges of Technology, 41012 Abu Dhabi, United Arab Emirates. ${ }^{\square}$ email: janna@upm.edu.my
} 
signal peptides that target the initial translation products towards the plastid ${ }^{3}$. A number of plant monoterpene and sesquiterpene synthases of molecular masses ranging from 50 to $100 \mathrm{kDa}$ (monomers or homodimers) have been isolated and characterized with similar properties such as requirement for a divalent metal ion, having $\mathrm{pI}$ value near 5.0 and $\mathrm{pH}$ optimum within a unit of neutrality ${ }^{4}$.

Despite the lack of significant sequence similarities, terpene synthases share highly conserved tertiary and quaternary structural features dominated by $\alpha$-helical folds known as class I terpene synthase fold ${ }^{5,6}$. These proteins consist entirely of $\alpha$-helices and short connecting loops and turns that are organized into two structural domains of a non-functional N-terminus and a catalytically active C-terminus ${ }^{7}$. The class I terpene synthases which include monoterpene and sesquiterpene synthases utilize a trinuclear magnesium cluster coordinated by two conserved metal-binding motifs (DDxxD and NSE/DTE) to initiate catalysis ${ }^{8}$. The trinuclear magnesium cluster facilitates orientation of the substrate diphosphate moiety in the active site and triggers substrate ionization that generates reactive carbocation intermediates which undergo a series of cyclization, hydride shifts or other arrangements until the reactions are terminated by protons loss or by the addition of water ${ }^{7,9}$. The ligand binding causes conformational changes that cap and sequester the active site, thereby protecting the reactive carbocation intermediates from premature quenching by bulk solvents ${ }^{5,8}$.

One of the most fascinating features of the terpene synthases group is its ability to form a single product or multiple products from a sole substrate $e^{4,7,10,11}$. Furthermore, some terpene synthases exhibit multi-substrate abilities by synthesizing terpenes of different chain lengths depending on the corresponding substrate availability ${ }^{12-15}$. The structural basis of fidelity and promiscuity of the terpene synthases is related to the contour of the active site that serves as a template for catalysis by ensuring substrates and intermediates bind in the proper conformations, thereby controlling the formation of final catalysis product $(s)^{16-18}$. Accordingly, the active site contours are product-like especially for high fidelity synthases to ensure the generation of specific product $(s)^{8}$.

Linalool/nerolidol synthase is a multi-substrate enzyme with the capability to use GPP or FPP as a substrate, leading to the synthesis of linalool or nerolidol, respectively. Linalool participates in a complex interplay between pollinator attraction and plant defense against herbivory by attracting natural enemies of the herbivores ${ }^{19,20}$. Similarly, nerolidol has been identified as a potent signal that induces accumulation of defense-related compounds with extensive natural anti-herbivore or anti-pathogen effects ${ }^{21,22}$. These compounds are widely used as fragrance materials in cosmetic products including perfumes, lotions and shampoos, and in non-cosmetic products such as detergents and cleansers. Isolation and characterization of this enzyme were reported from Plectranthus amboinicus $^{15}$, Rosa chinensis ${ }^{14}$, Hedychium coronarium ${ }^{23}$, Vitis vinifera ${ }^{24}$ and Antirrhinum majus ${ }^{13}$ which showed that this type of bifunctional enzyme is widespread across multiple plant species. The multisubstrate activity may confer advantages on plants to adapt rapidly in response to changes in the substrate profile under perturbation of metabolism in stressed plants, as well as under certain developmental changes without compromising their central metabolism ${ }^{12}$.

In our previous study, a putative monoterpene synthase gene (PamTps1) was isolated from P. amboinicus and introduced into the E. coli Rosetta ${ }^{\text {ax }} 2$ (DE3), which resulted in the production of linalool and nerolidol. Functional characterization demonstrated that this multi-substrate enzyme predominantly catalyzed formation of linalool and nerolidol from GPP and FPP, respectively, and was designated as a linalool/nerolidol synthase (Accession no: QGN03393 ${ }^{15}$. To learn more about PamTps1, biochemical characterization such as $\mathrm{pH}$ dependence, temperature dependence, divalent metal ion and substrate preferences, and kinetic properties were investigated. A reliable 3D homology model depicting the conformation of the P. amboinicus linalool/nerolidol synthase and the position of both GPP and the FPP substrates in the active site were also predicted in this analysis. Identification of the key residues involved in the active site architecture and catalysis reaction were also conducted. This model will serve as a basis for protein engineering to improve this bifunctional synthase with regard to product specificity or catalytic efficiency, and as a guide to future exploitations of this enzyme in terpenoids production.

\section{Results and discussion}

Effects of $\mathrm{pH}$ and temperature on PamTps1 activity. The PamTps1 activity was investigated using GPP as a substrate over a $\mathrm{pH}$ range of 5.5 to 9.0. At $\mathrm{pH}$ 6.5, the maximum catalytic activity was observed but was reduced to less than $10 \%$ of the maximum activity at $\mathrm{pH} 5.5$ and $\mathrm{pH} 9$ (Fig. 1A). This result was similar to the $3 R$-linalool synthase of Mentha citrate which exhibited an optimum $\mathrm{pH}$ close to $\mathrm{pH} 6.5$ and a half maximum velocity at $\mathrm{pH} 7.5^{25}$. Typically, the optimal $\mathrm{pH}$ for terpene synthases is within a unit of neutrality as reviewed by Bohlmann et al. ${ }^{4}$. Previously characterized plant linalool synthases showed an optimal $\mathrm{pH}$ range of 6.0$8.0^{23,26-29}$. It was also noted that monoterpene synthases had a $\mathrm{pH}$ optima of 6-7 that correlated with the $\mathrm{pH}$ of the chloroplast in plants ${ }^{30-32}$, which corroborated the findings of PamTps1. Solvolytic decomposition of GPP to linalool in the presence of divalent cation was reported to occur under acidic condition ${ }^{33}$. As a result, the effect of $\mathrm{pH}$ below 5.5 could not be determined accurately due to an increase of substrate decomposition to linalool, which was also observed by Crowell et al..$^{25}$.

The enzymatic activity of Pam Tps1 was conducted at temperatures ranging from 25 to $50^{\circ} \mathrm{C}$. Optimal catalytic activity was observed at $30^{\circ} \mathrm{C}$, with only half of the maximal activity noted at $25^{\circ} \mathrm{C}$ and $37^{\circ} \mathrm{C}$ (Fig. 1B). The observed result was similar to the temperature range $\left(30-40^{\circ} \mathrm{C}\right)$ reported for plant terpene synthases such as ocimene synthase of Lilium $^{26}$, linalool synthase of coriander ${ }^{34}$ and Hedychium coronarium ${ }^{23}$, cineole synthase of lavender ${ }^{35}$ and $\beta$-sesquiphellandrane synthase of Persicaria minor ${ }^{36}$. The catalytic activity of Pam Tps 1 dropped drastically beyond the optimum temperature, with only less than $10 \%$ of the full velocity retained at $50{ }^{\circ} \mathrm{C}$. This could probably be linked to the destabilization of the three-dimensional structure of the enzyme at higher temperatures and ultimately contributed to denaturation and irreversible loss of activity ${ }^{37}$. 

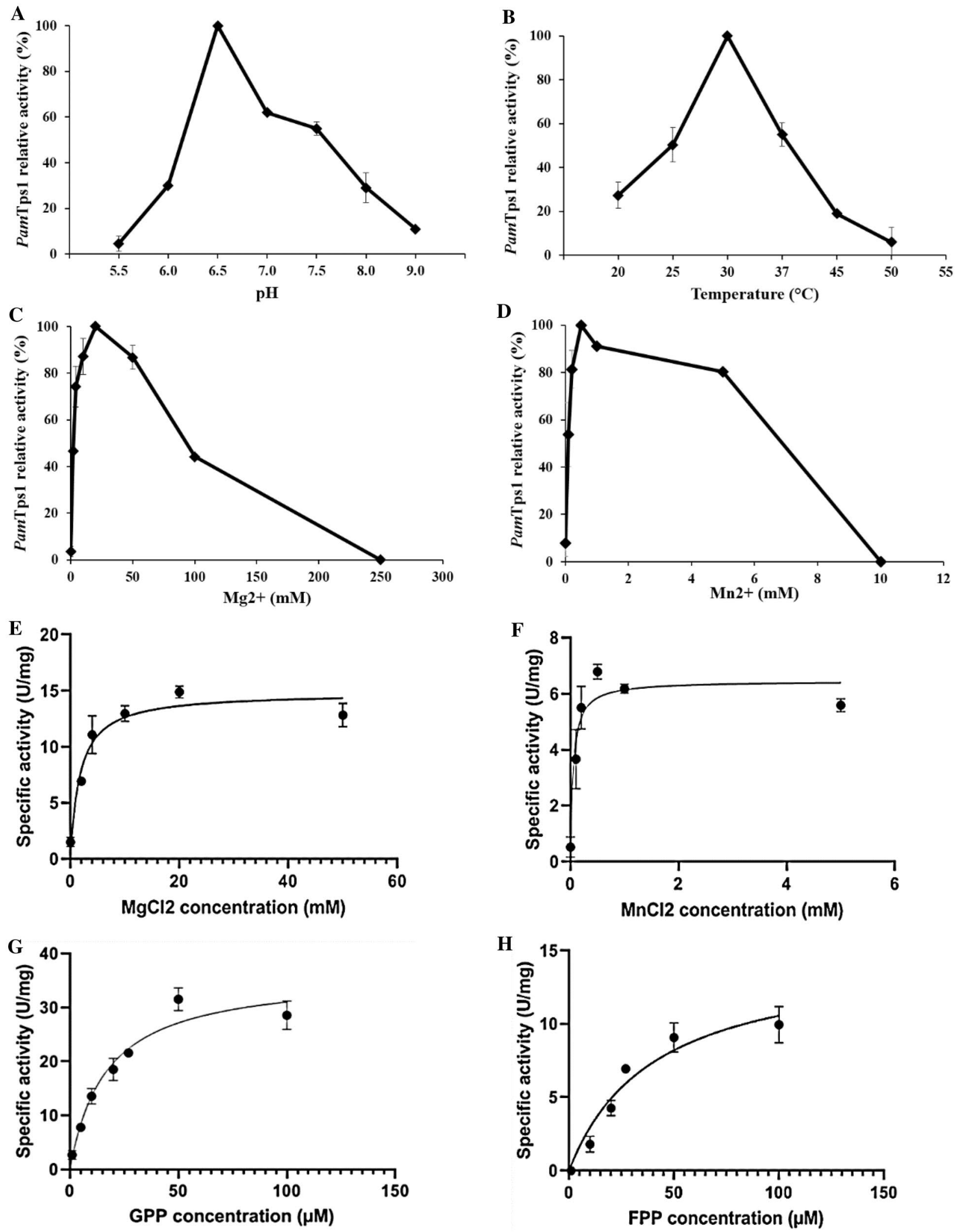

Figure 1. Biochemical characterization of PamTps1. (A) pH; (B) Temperature; (C) $\mathrm{Mg}^{2+}$ concentrations; (D) $\mathrm{Mn}^{2+}$ concentrations. Michaelis-Menten plot of PamTps1 at different concentrations of $(\mathbf{E}) \mathrm{Mn}^{2+} ;(\mathbf{F}) \mathrm{Mg}^{2+}$; (G) GPP and (H) FPP. The saturation curve was constructed using Michaelis-Menten equation by hyperbolic regression. Values were reported as the mean of relative activity \pm SD of triplicate analysis. 


\begin{tabular}{|l|l|l|l|l|}
\hline Metal/substrate & $\boldsymbol{V}_{\max }\left(\boldsymbol{\mu m o l} \mathrm{mg}^{-1}\right)$ & $\boldsymbol{K}_{\mathrm{m}}$ & $\boldsymbol{k}_{\text {cat }}\left(\mathrm{s}^{-1}\right)$ & $\boldsymbol{k}_{\text {cat }} / \boldsymbol{K}_{\mathrm{m}}$ \\
\hline $\mathrm{Mg}^{2+\star}$ & $14.84 \pm 1.40$ & $1.74 \pm 0.35 \mathrm{mM}$ & 0.10 & $0.058 \mathrm{mM}^{-1} \mathrm{~s}^{-1}$ \\
\hline $\mathrm{Mn}^{2+\star}$ & $6.46 \pm 0.35$ & $0.05 \pm 0.00 \mathrm{mM}$ & 0.04 & $0.800 \mathrm{mM}^{-1} \mathrm{~s}^{-1}$ \\
\hline $\mathrm{GPP}^{\star *}$ & $24.16 \pm 3.75$ & $16.72 \pm 1.32 \mu \mathrm{M}$ & 0.16 & $9.57 \times 10^{-3} \mu \mathrm{M}^{-1} \mathrm{~s}^{-1}$ \\
\hline $\mathrm{FPP}^{* *}$ & $14.85 \pm 2.80$ & $40.47 \pm 3.83 \mu \mathrm{M}$ & 0.10 & $2.47 \times 10^{-3} \mu \mathrm{M}^{-1} \mathrm{~s}^{-1}$ \\
\hline
\end{tabular}

Table 1. Kinetic properties of PamTps1. ${ }^{*}$ Values when $\mathrm{Mg}^{2+}$ and $\mathrm{Mn}^{2+}$ were used in the presence of $27 \mu \mathrm{M}$ GPP. ${ }^{\star *}$ Values for GPP and FPP were measured in the presence of $20 \mathrm{mM} \mathrm{Mg}^{2+} . V_{\max }=$ Maximal velocity; $K_{\mathrm{m}}=$ Michaelis-Menten constant; $k_{\text {cat }}=$ Turnover number $k_{c a t} / K_{\mathrm{m}}=$ Catalytic efficiency. Values were reported as the mean of relative activity \pm SD of triplicate analysis.

Effects of divalent metals on PamTps1 activity. Terpene synthases have an absolute requirement for a divalent metal ion such as $\mathrm{Mg}^{2+}$ or $\mathrm{Mn}^{2+}$ as a cofactor. The role of divalent metal ion in terpene synthases catalysis has been widely discussed and presumably involved in both substrate binding and catalysis ${ }^{8,17}$. Chelation of metal ion such as $\mathrm{Mg}^{2+}$, neutralizes two of the three negative charges of the diphosphate moiety of the substrate, thereby assisting the ionization of the allylic substrate into highly reactive carbocation intermediates ${ }^{38}$. Thus, divalent metal ions preferences of PamTps1 and their influence on the catalytic activity were evaluated at different concentrations of $\mathrm{Mg}^{2+}(0-250 \mathrm{mM})$ and $\mathrm{Mn}^{2+}(0-10 \mathrm{mM})$.

In the absence of a divalent metal ion, the PamTps1 activity was negligent. However, the activity was restored by the provision of either $\mathrm{Mg}^{2+}$ or $\mathrm{Mn}^{2+}$, which suggested an absolute requirement for a metal ion cofactor for catalytic activity (Fig. 1C,D). A maximal activity was obtained with $\mathrm{Mn}^{2+}$ at $0.5 \mathrm{mM}$, but was inhibited as $\mathrm{Mn}^{2+}$ concentration increased to $10 \mathrm{mM}$ (Fig. 1D). Other characterized plant terpene synthases demonstrated maximum activity with manganese concentrations at less than $1.0 \mathrm{mM}^{28,39,40}$. On the other hand, in the presence of $\mathrm{Mg}^{2+}$, the catalytic activity of PamTps1 increased steadily from $2 \mathrm{mM}$ to a maximum activity at $20 \mathrm{mM}$, but was inhibited at $250 \mathrm{mM}$ (Fig. 1C). This optimal concentration of $\mathrm{Mg}^{2+}$ finding was also observed in M. citrata linalool synthase $^{25}$, Citrus sinensis limonene synthase ${ }^{40}$ and Japanese pepper terpene synthases ${ }^{39}$. In this study, Pam Tps 1 showed a preference for $\mathrm{Mg}^{2+}$ for catalysis with 2.1 folds increase in activity compared to $\mathrm{Mn}^{2+}$. Likewise, other characterized plant terpene synthases that favored $\mathrm{Mg}^{2+}$ over $\mathrm{Mn}^{2+}$ included linalool/nerolidol synthase 1 and $2^{13}$, Artemisia annua monoterpene synthases ${ }^{41}$, Lilium 'Siberia' terpene synthase ${ }^{26}$ and Santalum album terpene synthases $^{42}$. In contrast, linalool synthase of lavender ${ }^{28}$ and C. sinensis limonene synthase ${ }^{40}$ showed preferences for $\mathrm{Mn}^{2+}$ as a cofactor with high terpene yields when 1-5 $\mathrm{mM}$ of $\mathrm{Mn}^{2+}$ were used.

Kinetic parameters of PamTps1. In this study, PamTps1 activity was inhibited when $\mathrm{Mg}^{2+}$ and $\mathrm{Mn}^{2+}$ concentrations beyond $50 \mathrm{mM}$ and $5 \mathrm{mM}$, respectively, were used. Therefore, the $K_{\mathrm{m}}$ value was estimated by a non-linear Michaelis-Menten curve using lower concentrations of $\mathrm{Mg}^{2+}$ and $\mathrm{Mn}^{2+}$ (Fig. 1E,F) which gave $1.74 \pm 0.35 \mathrm{mM}$ and $0.05 \pm 0.001 \mathrm{mM}$, respectively, (Table 1). These values were comparable to those obtained with kiwi terpene synthases ${ }^{43}$, snapdragon linalool/nerolidol synthase ${ }^{13}$ and sweet basil geraniol synthase ${ }^{44}$. Nevertheless, in some reported metal ions studies, there are other terpene synthases that recorded $K_{\mathrm{m}}$ values of less than $1 \mathrm{mM}^{23,27,45}$ while higher $K_{\mathrm{m}}$ values were also noted in some terpene synthases including $A$. annua linalool synthase $^{46}$ and $\gamma$-terpinene synthases ${ }^{10,47}$. Although $K_{\mathrm{m}}$ value for PamTps1 was substantially lower when using $\mathrm{Mn}^{2+}$, its $V_{\max }$ value was only $43 \%$ of that with $\mathrm{Mg}^{2+}$. It is presumed that PamTps1 is more likely to operate with $\mathrm{Mg}^{2+}$ cofactor in planta due to the higher concentration of $\mathrm{Mg}^{2+}$ in plant cells as compared to the $\mathrm{Mn}^{2+} 48,49$.

Kinetic characterization of PamTps1 for GPP and FPP was performed below $100 \mu \mathrm{M}$ since higher concentrations inhibited its catalytic activity (Fig. 1G,H). The apparent $K_{\mathrm{m}}$ value of PamTps1 for GPP was $16.72 \pm 1.32 \mu \mathrm{M}$, which was well within the range of $K_{\mathrm{m}}$ values reported in other plant monoterpene synthases (Table 1$)^{40,41}$, but lower compared to linalool synthases from $H$. coronarium $(20.54 \pm 4.52 \mu \mathrm{M})^{23}$, Cinnamomum osmophloeum $(54.19 \mu \mathrm{M})^{50}$, L. angustifolia $(55.8 \pm 4.1 \mu \mathrm{M})^{28}$ and $M$. citrata $(25 \pm 6.00 \mu \mathrm{M})^{25}$. Nonetheless, linalool synthases from snapdragon ${ }^{13}$, A. arguta $^{27}$ and A. chinensis ${ }^{51}$ exhibited $K_{\mathrm{m}}$ values below $10 \mu \mathrm{M}$ which suggested that these enzymes have a higher affinity for GPP. On the other hand, PamTps1 $K_{\mathrm{m}}$ value of $40.47 \pm 3.83 \mu \mathrm{M}$ for FPP was 2.4 folds higher than that for GPP, which signified that PamTps1 had a higher binding affinity for GPP.

From the abovementioned results, it can be inferred that PamTps1 has a lower affinity for FPP and become saturated at a higher substrate concentration to reach its maximal velocity $\left(V_{\max }=14.85 \pm 2.80 \mu \mathrm{mol} \mathrm{mg}^{-1}\right)$. PamTps1 has a greater affinity for GPP than FPP as anticipated for a monoterpene synthase, where a lower concentration of GPP was required to achieve $V_{\max }$ of $24.16 \pm 3.75 \mu \mathrm{mol} \mathrm{mg}^{-1}$. Similar observation was noted in the snapdragon linalool/nerolidol synthases that exhibited higher substrate affinity towards GPP than to FPP ${ }^{13}$. The turnover rate $\left(k_{\text {cat }}\right)$ for both substrates in the current study were $0.16 \mathrm{~s}^{-1}$ and $0.10 \mathrm{~s}^{-1}$ for GPP and FPP, respectively, which was within the range of monoterpene $\left(0.01-1.0 \mathrm{~s}^{-1}\right)$ and sesquiterpene $\left(0.03-0.5 \mathrm{~s}^{-1}\right)$ synthases recorded $\mathrm{d}^{52,53}$, and the low $k_{c a t}$ values reflected that PamTps 1 is a relatively slow enzyme. Terpene synthases are typically slow enzymes, which is a general feature of the enzymes involved in secondary metabolism and is approximately 30 folds slower than those involved in central metabolism ${ }^{54}$. The catalytic efficiency $\left(k_{c a t} / K_{\mathrm{m}}\right)$ of GPP was 3.9 folds higher than FPP, further suggesting that PamTps1 recognized GPP more efficiently, which was in accordance with the abovementioned expectations. This may also be linked to the fact that PamTps1 was a plastid-targeted enzyme, where the GPP pool was located. Parallel observations were seen in lavender ${ }^{28}$ and Freesia ${ }^{55}$. 
Secondary structure prediction. The secondary structure of PamTps1 was predicted using PSIPRED server $^{56}$ followed by identification and annotation of the protein domain using MOTIF and SMART ${ }^{57}$. The PSIPRED tool predicted that the secondary structure of PamTps1 would consist entirely of $a$-helices (24 $\alpha$-helices) connected by coils, with no strands or $\beta$-sheets observed except for the two extended strands located at the $\mathrm{N}$-terminal signal peptide region (Fig. S1). Through domain analysis, it was revealed that these $\alpha$-helices were organized into two structural domains of N-terminal (residues: 66-245) (Pfam: PF01397) and C-terminal metal binding domain (residues: 277-540) (Pfam: PF03936) with domain boundary located at residue M271 as determined by DomPRED. These predictions are in agreement with general features of most plant terpene synthases that adopt an $\alpha$-helical architecture, which are organized into two domains of $\mathrm{N}$-terminal region that has structural similarity to glycosylhydrolases ${ }^{58}$ and the C-terminal domain containing the catalytic site ${ }^{5}$.

Protein homology modelling of the PamTps1. The PamTps1 was modeled on the crystal structure of Salvia officinalis (+)-bornyl diphosphate synthase (BPPS) $(1 \mathrm{~N} 24)^{5}$ using residues that correspond to the complete amino acid sequence in accordance to the $\mathrm{RRx}_{8} \mathrm{~W}$ motif. The chosen BPPS template featured a closed active site conformation with $\mathrm{Mg}^{2+}$ and its product, and shared $67.04 \%$ sequence identity. The residue numbers described hereafter corresponded to the numbering of amino acids immediately following the $\mathrm{RRx}_{8} \mathrm{~W}$ motif (Fig. S2). The predicted PamTps1 structure as shown in Fig. 2, revealed that the enzyme comprised of two structural domains of $\mathrm{N}$ - and $\mathrm{C}$-terminal, connecting with short loops and turns. The $\mathrm{N}$-terminal domain (residues 1-214) of PamTps1 consisted of $14 \alpha$-helices arranged in an $\alpha$-barrel with minor structural differences to that of BPPS ${ }^{5}$. Although there was no established catalytic function for this N-terminal domain, it was reported that this domain was involved in capping the active site pocket upon substrate binding, and presumably shielded the reactive carbocation intermediates from water as observed in the crystal structure of BPPS, Taxus brevifolia taxadiene synthase (PDB ID: 3P5R) and Gossypium arboretum $\delta$-cadinene synthase (PDB ID: 3G4F) ${ }^{5,9,59}$. The presence of this apparently non-functional N-terminal domain in terpene synthases may have been due to an evolutionary vestige from copalyl diphosphate synthase-kaurene synthase, which was the ancestor of all modern terpene synthases that possess both functional catalytic domains $s^{6,8,60}$.

The N-terminal domain contained two conserved motifs that were present in typical plant terpene synthases, namely the $\mathrm{RRx}_{8} \mathrm{~W}$ and LQLYEASFLL motifs. The tandem arginine motif was found in many plant monoterpene synthases and was thought to mark the approximate cleavage site of the plastid-targeting sequence ${ }^{6}$. A previous truncation study of this motif from a limonene synthase suggested that the RR motif was required for initial isomerization of GPP to linalyl diphosphate (LPP), owing to the inability of the truncated limonene synthase to accept GPP as a substrate, while still functioning with LPP as a substrate for the cyclization step ${ }^{6,61}$. These arginine residues may also contribute to the stabilization of the closed active site while still allowing flexibility that was necessary for the binding of two structurally different prenyl diphosphates (GPP and LPP) as observed in limonene synthase ${ }^{6}$. Since PamTps 1 did not undergo a cyclisation reaction, it was likely that the $\mathrm{RRx}_{8} \mathrm{~W}$ motif might only be involved in the capping of the PamTps1 active site and not in the catalysis reaction. The InterPro$\mathrm{Scan}$ analysis also predicted that the $\mathrm{RRx}_{8} \mathrm{~W}$ region acted as an active site lid in the PamTps1. Besides that, the LQLYEASFLL motif that was assumed to be part of the active site ${ }^{62,63}$ occurred as LQLYEASFLE in PamTps1, and there were no observable differences in the overall structure of the enzyme for amino acid substitution from leucine to glutamic acid.

The larger C-terminal domain (residues 215-542) adopted an $\alpha$-helical architecture known as class I terpene synthase fold which consisted of 16 -helices, where the hydrophobic pocket of the active site cavity was formed by six $\alpha$-helices (C, D, F, G, H and J) (Fig. 2). This domain was well conserved with an RMSD value of $0.190 \AA$ as compared to the BPPS. The C-terminal domain contained two metal binding motifs of the aspartate-rich DDxxD and NSE/DTE (evolved from a second aspartate-rich region) to form a consensus sequence of $(\mathrm{L}, \mathrm{V})$ $(\mathrm{V}, \mathrm{L}, \mathrm{A})(\mathbf{N}, \mathbf{D}) \mathrm{D}(\mathrm{L}, \mathrm{I}, \mathrm{V}) \mathrm{x}(\mathrm{S}, \mathbf{T}) \mathrm{xxxE}$. The NSE/DTE motif appeared to be less well conserved amongst the plant terpene synthases as compared to the DDxxD motif. Both the DDxxD and NSE/DTE motifs were reported to bind to a trinuclear magnesium cluster involved in the fixation of the diphosphate substrate ${ }^{5,64,65}$. The Pam Tps1 also contained other motifs that were thought to be part of the terpene synthases active site, such as RxR and GTLxEL ${ }^{63,66}$ which occurred as RDR and GTLDEL in PamTps1 and were located 35 amino acids upstream and two amino acids downstream of the DDxxD, respectively.

Protein structural alignment or superimposition allows homology establishment between template and protein model based on the 3D protein conformation as a protein structure was more conserved than its sequence during evolution. Superimposition of the PamTps1 model with BPPS template using Chimera with a-carbon RMSD fitted to $0.203 \AA$ showed that the two structures were exceptionally similar (Fig. 3).

Validation of the PamTps1 model. The reliability of the model was first evaluated by the GMQE and Qualitative Model Energy Analysis (QMEAN) scores provided by the SWISS-MODEL tool. The GMQE score is expressed as a number between 0 and 1 , where higher numbers indicate higher reliability of the model ${ }^{68}$. The QMEAN Z-score provides an estimate degree of structural features similarity observed in the model with scores around 0 indicate good agreement between model structure and template ${ }^{69}$. The PamTps1 model scores of 0.82 and -1.32 for respective GMQE and QMEAN showed that the built model was reliable and satisfactory. Further validation by PROCHECK to assess the stereochemical quality of generated model showed that $92.8 \%$ of Pam Tps 1 residues fall in most favored regions, $6.6 \%$ residues in additional allowed regions, $0.2 \%$ residues in generously allowed regions and only $0.4 \%$ residues in the disallowed regions suggesting the acceptability of the modeled structure (Fig. S2, Table S3). PROVE analysis revealed that the quality of the predicted 3D structure of PamTps1 model was good and reliable with the respective Z-score mean and Z-score RMS for the entire structure of 0.487 and 1.421, respectively. The ERRAT analyses statistic of non-bonded interactions between different 


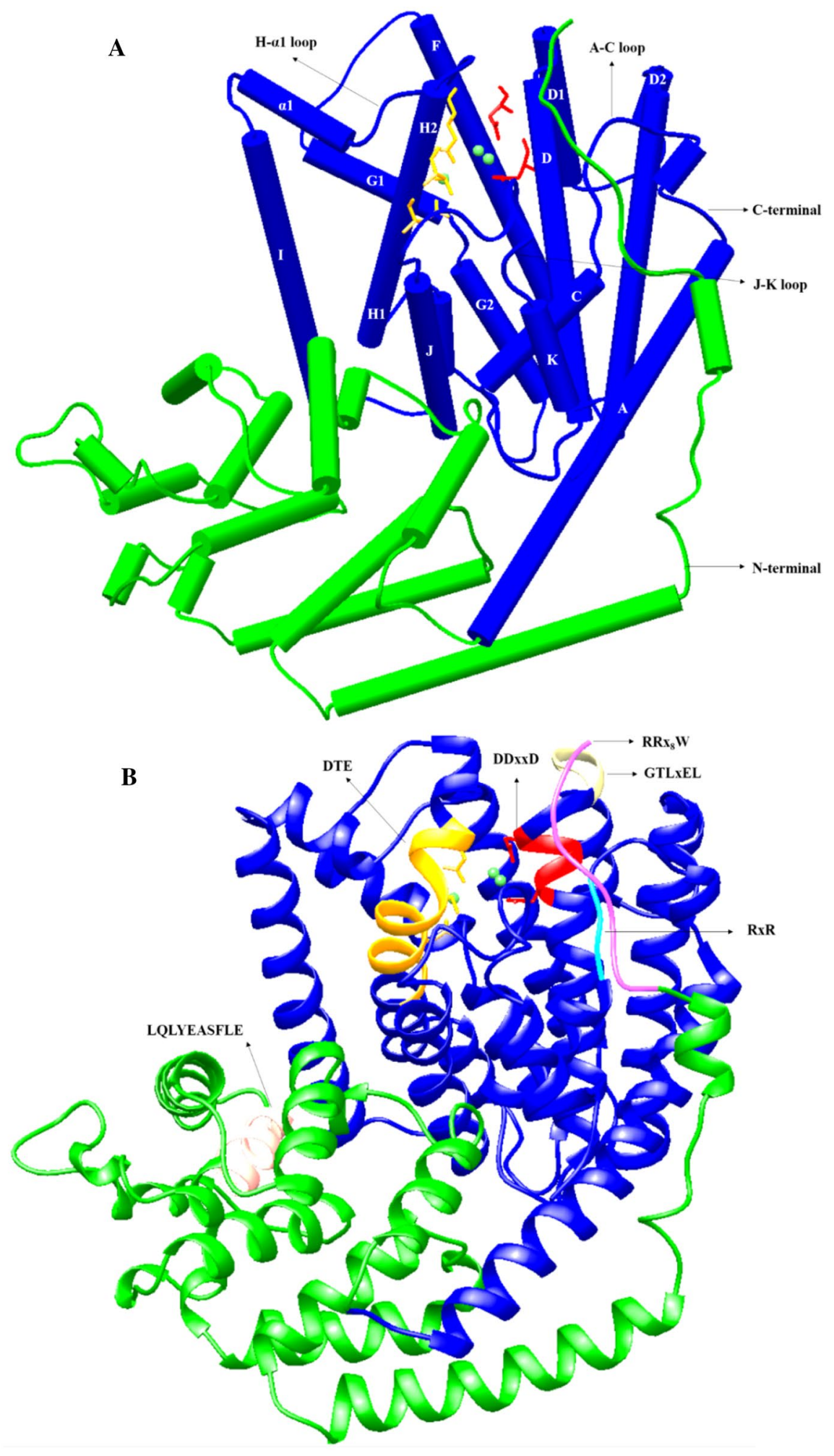

Figure 2. Protein homology modelling of PamTps1 using SWISS-MODEL server showed the structural domains and the active site of the enzyme. (A) model structure of PamTps1 made up of $\alpha$-helices with $\mathrm{N}$-terminal domain (green) and C-terminal domain (blue). (B) Ribbon view of PamTps1 model. The helical segment was designated according to Tarshis et al. ${ }^{67}$. All conserved motifs were labelled in the figure and $\mathrm{Mg}^{2+}$ was illustrated as green spheres. 


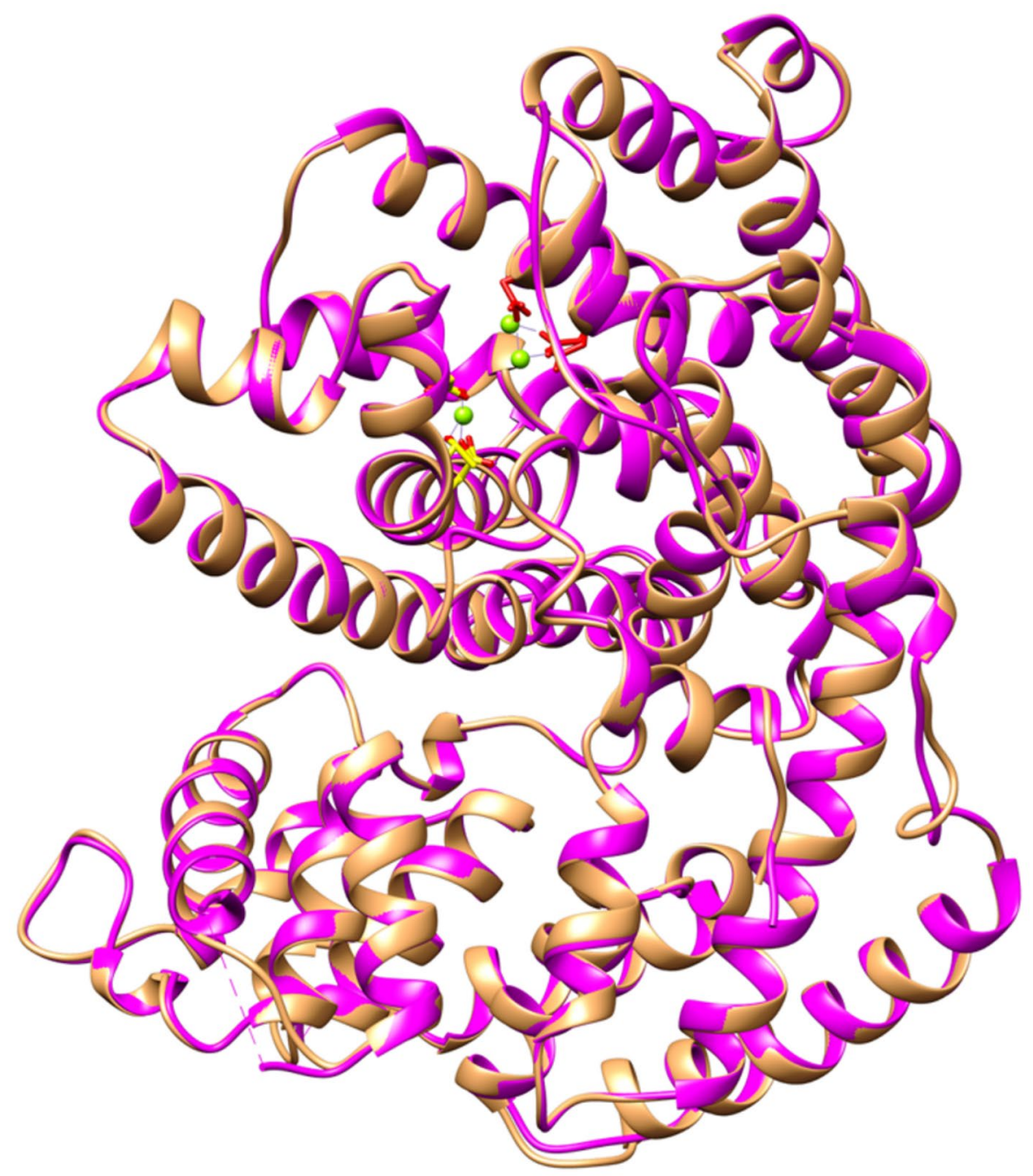

Figure 3. Superimposition of PamTps1 model (purple) with BPPS template (brown) using Chimera. The a-carbon RMSD value of $0.203 \AA$ indicated the two structures were exceptionally similar. The aspartate-rich motif was red, the DTE motif was orange and the green spheres were magnesium ions.

atom types based on characteristic atomic interactions ${ }^{97}$. The overall ERRAT quality factor value is expressed as the percentage of the protein for which the calculated value is less than the $95 \%$ rejection limit. A good highresolution structure typically yields values of $95 \%$ or higher, and the PamTps1 model yielded an overall quality factor of $95.88 \%$, which was very satisfactory. Another program used for validation of protein structure was the Verify3D, which determines compatibility of an atomic model (3D) with its own amino acid sequence (1D) by assigning structural class based on its location and environment ${ }^{98}$. The Verify3D analysis of PamTps1 model revealed that $95.73 \%$ of the residues had an average $3 \mathrm{D}-1 \mathrm{D}$ score $\geq 0.2$. As the cut-off score $\geq 0$, this implies that the predicted model was valid. ProSA was used to check the 3D model of PamTps1 for potential errors where positive value of the z-score corresponded to problematic or erroneous region of a model. The Z-score of - 12 for PamTps1 model was within the acceptable range of X-ray studies and this value was close to the value of the template (-10.92) suggesting that the predicted model was reliable and close enough to experimentally determine structure (Fig. S2, Table S3).

Molecular docking of PamTps1 with prenyl diphosphate substrates. To gain further insight into the active site of the enzyme investigated here, the model structure of PamTps1 was carried out with molecular docking using GPP $\left(\mathrm{C}_{10}\right)$ and FPP $\left(\mathrm{C}_{15}\right)$ substrates. Docking of the prenyl diphosphate substrates yielded multiple docking positions. The criteria for choosing the best docking position were based on the lowest docking score and the number of hydrogen bonds between the substrate and the amino acid residues. A docking position with the least docking score has the highest affinity towards the ligand, and hence is the best docked conformation. Hydrogen bonds contribute to the stability of proteins and specificity of protein-ligand interactions, which is also an important consideration for selection of the docking position ${ }^{70}$. The docking results were further analyzed using Chimera and LigPlot + to generate 2D and 3D ligand-protein interaction diagrams, respectively. 
A

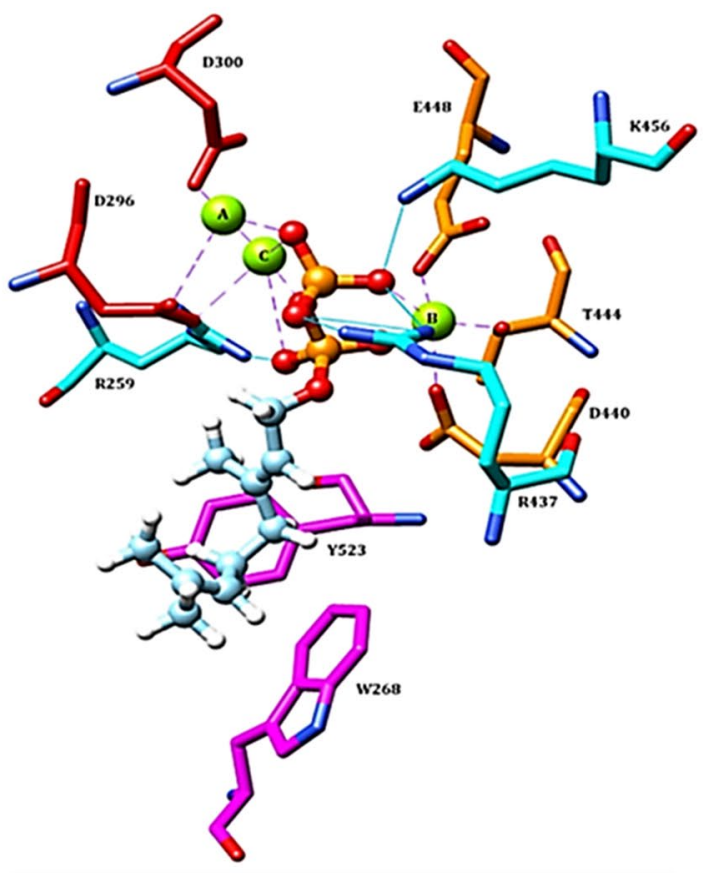

C

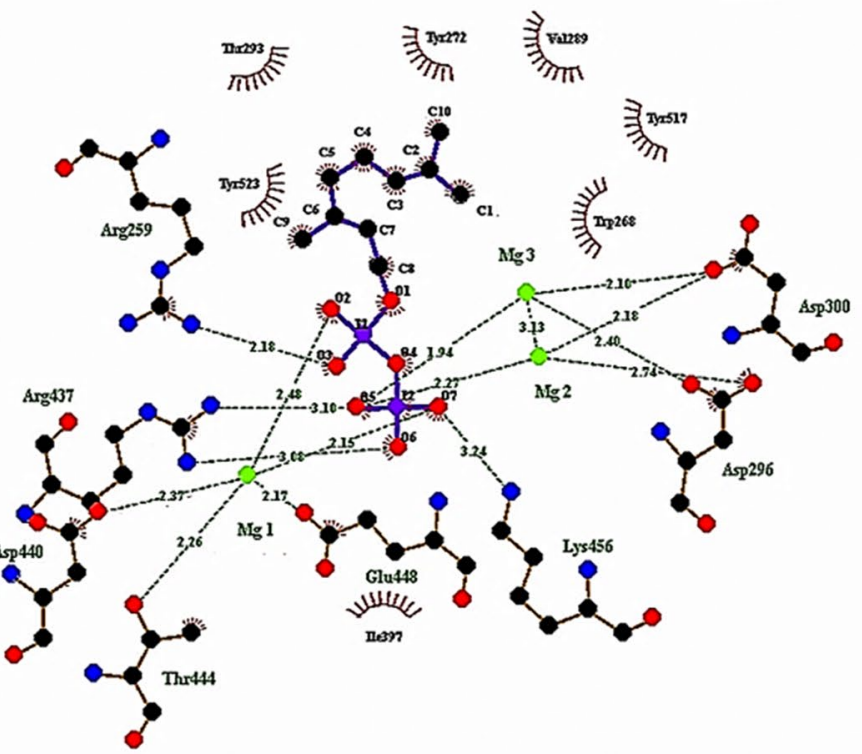

B
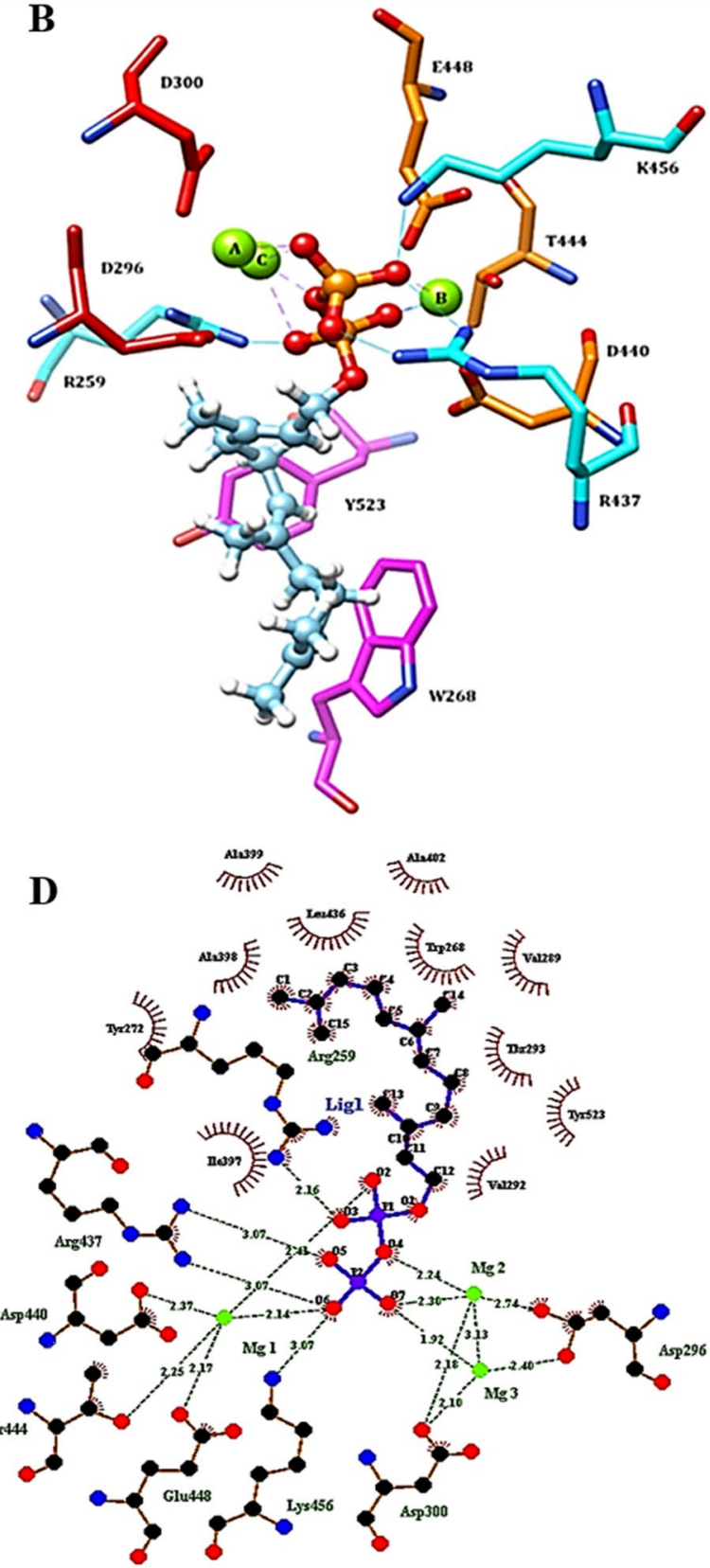

Figure 4. Ligand-PamTps1 interactions. Three-dimensional (3D) view of (A) GPP and (B) FPP docking at PamTps1 active site. The red-orange balls and stick chains represent $\mathrm{PPi}$, green spheres are the $\mathrm{Mg}^{2+}$, the red side chains are the DDxxD motif, the orange side chains are the DTE motifs, the blue side chains are the hydrogen bond donor residues, the magenta side chains represent the aromatic residues and the cyan lines are the hydrogen bonds. Two-dimensional (2D) view of (C) GPP and (D) FPP docking at PamTps1 active site. Hydrogen bonds are shown as green dotted lines, $\mathrm{Mg}^{2+}$ are shown in green spheres and spoked arcs represent residues making non-bonded contacts with the hydrophobic tail of the ligand. Details of the docking result are summarized in Table S2.

Docking of GPP and FPP substrates confirmed that the active site of PamTps1 was located at the C-terminal domain, proximate to the location of the $\mathrm{Mg}^{2+}$ cofactor (Fig. 4). A two-dimensional representation of $\mathrm{Mg}^{2+}$ interaction with the amino acid residues and substrate (ligand) was displayed in Fig. 4C,D. This concurred with earlier observations using SWISS-MODEL and InterProscan that the diphosphate (PPi) moiety of the prenyl substrates interacted with the highly conserved aspartate-rich (D296DVYD300) and NSE/DTE (LAD440DLGT444APFE448) motifs via complexed $\mathrm{Mg}^{2+}$, in which the boldface residues were coordinated to the metal ions. The first and third aspartate residues in the aspartate-rich motif, D296 and D300, were coordinated to $\mathrm{Mg}^{2+}{ }_{\mathrm{A}}$ and $\mathrm{Mg}^{2+}{ }_{\mathrm{C}}$, which were identical to the BPPS, avian FPP synthase ${ }^{67}$, taxadiene synthase ${ }^{9}$, and $M$. spicata limonene synthase ${ }^{6}$. The second metal-binding region comprised of D440, T444 and E448 of the helix H coordinated to the $\mathrm{Mg}^{2+}{ }_{\mathrm{B}}$. Similar metal ion coordination by the corresponding residues was also observed in trichodiene 


\begin{tabular}{|l|l|l|l|l|}
\hline Metal & Ligand & Geometry & gRMSD & Vacancy \\
\hline $\mathrm{Mg}^{2+}$ & $\mathrm{O}$ & Octahedral & Acceptable & Borderline \\
\hline $\mathrm{Mg}^{2+}$ & $\mathrm{O}$ & Square planar & Acceptable & Borderline \\
\hline $\mathrm{Mg}^{2+}$ & $\mathrm{O}$ & Octahedral & Acceptable & Outlier \\
\hline
\end{tabular}

Table 2. Metal-binding site geometry analysis.

synthase $\mathrm{e}^{71}, 5$-epi-aristolochene synthase $\mathrm{e}^{72}$ and taxadiene synthase $\mathrm{e}^{9}$. The distances between $\mathrm{Mg}^{2+}$ cofactor and the corresponding residues were summarized in Table S1. The ideal distance for metal ion coordination was between 2.0 and $2.2 \AA$, which was more typically observed in higher-resolution structures ${ }^{73}$. It was revealed that the coordination distance with the metal ion for PamTps1 was within the range of 2.0-2.75 $\AA$, which was longer than what was expected for $\mathrm{Mg}^{2+}$ coordination. Shorter metal-ligand distances resulted in tighter first coordination sphere ligands, resulting in less wiggle room in the first coordination sphere, and therefore less deviation from the ideal octahedral geometry ${ }^{74}$. Magnesium has the tightest initial coordination sphere closest to ideal octahedral geometry, with a typical Mg-O distance of around $2.1 \AA^{74}$. Validation of metal-binding sites of PamTps1 revealed that two of the three metal ions exhibited octahedral geometry, while the third had an outlier geometry (Table 2). The gRMSD measures overall deviation of the observed geometry angle from the ideal geometry angle ${ }^{75}$, and PamTps1 model showed acceptable gRMSD values for the trinuclear magnesium cluster binding sites. The vacancy calculates percentage of vacant coordination sites for a given geometry ${ }^{75}$. This analysis, however, revealed borderline and outlier vacancy values, which probably explained the longer metal coordination distances between magnesium ion and binding sites as discussed previously (Table S1).

In addition to metal coordination interactions, the PPi moiety of GPP and FPP were also predicted to accept hydrogen bonds from R259, R437 and K456 residues (Fig. 4; Table S2). Similarly, this finding was observed in other reported plant terpene synthases where PPi binding was accommodated by hydrogen bonds donated from two arginine and one lysine residues ${ }^{5,8,72}$. The R259 of PamTps1 derived from the R259DR motif may serve as a proton donor to thermodynamically support the PPi cleavage by protonation after the first reaction step ${ }^{76-78}$. Mutational analysis of this residue showed a loss of catalytic activity suggesting the important role of this arginine residue in restricting the $\mathrm{PPi}^{79}$. The $\mathrm{R} 437$ derived from the extended second metal binding motif (LR437LADDLGTAPFE) in PamTps1 was also reported to donate hydrogen bond to the PPi of the substrate as observed with the bornyl diphosphate synthase ${ }^{5}$. The K456 residue of the PamTps1 that was a part of the conserved lysine residue amongst Tpsb terpene synthases was located at the $\mathrm{H}-\alpha 1$ loop and hydrogen bonded with the PPi of the substrate. The H- $\alpha 1$ loop lysine residue was also observed to donate hydrogen bond to the PPi in the BPPS crystal structure and limonene synthase $\mathrm{e}^{6}$. The coordination of three metal ions and hydrogen bond interactions with basic residues of lysine and/or arginine presumably triggered the ionization of the substrate to yield carbocation intermediates that led to the production of terpenoids ${ }^{80,81}$. The substrate coordination and distance with PamTps1 residues and $\mathrm{Mg}^{2+}$ are summarized in Table S2. Based on the proposed mechanism of 5-epi-aristolochene synthase ${ }^{72}$ and Abies grandis $\alpha$-bisabolene synthase ${ }^{82}$, the metal-dependent ionization of the substrate resulted in the generation of a negatively charged PPi that was stabilized by $\mathrm{Mg}^{2+}$ ions and three basic residues, and which created a positively charged region that drew the PPi away from the carbocations in the hydrophobic active pocket. Thus, the three $\mathrm{Mg}^{2+}$ ions and the three basic residues served as the PPi recognition motif in the active site, allowing proper orientation of the substrate while activating the PPi to initiate ionization and catalysis ${ }^{8}$.

The active site of terpene synthases was also characterized by the presence of several aromatic residues crucial for the stabilization of the carbocation intermediates ${ }^{5,8,9,79}$. The docking results revealed that the non-polar hydrocarbon groups of GPP and FPP were buried in the hydrophobic area of the active site surrounded by aliphatic and aromatic residues (Fig. 4C,D). The $\mathrm{C}_{10}$ tail of the GPP formed hydrophobic interactions with W268, Y272, V289, T293, I397, T517 and Y523 residues. Meanwhile the W268, Y272, V289, V292, T293, I397, A398, A399, A402, L436 and Y523 residues participated in non-bonded interactions with the $\mathrm{C}_{15}$ group of the FPP. Among the active site residues, the non-polar hydrocarbon group of GPP and FPP were located in the aromatic pair's area surrounded by residues Y523 of the J-K loop and W268 of the helix C at the bottom of the PamTps1 active site (Fig. 4A,B). Sequences comparison against other terpene synthases suggested that the W268 was a conserved residue, whereas the position equivalent to Y523 could be occupied by aromatic residues of histidine, phenylalanine or tyrosine as mutation of these residues resulted in catalytically impaired catalyst ${ }^{6,8,79,83}$. According to Brandt et al. ${ }^{76}$, the nature and position of these aromatic amino acid residues at the active site of terpene synthases determined the docking orientation of the intermediate prenyl cation and therefore product specificity. In amorphadiene synthase, the aromatic phenylalanine residue (residue in the same position of Y523 of PamTps1) was similarly involved in positioning of the FPP substrate in the active site, which subsequently stabilized the carbocation intermediates ${ }^{84}$. A similar observation was also reported by Zhang et al.$^{85}$ with Nicotiana tabacum 5 -epi-aristolochene synthase (TEAS) that catalyzed the cyclisation of FPP into bicyclic 5-epi-aristolochene. Mutational analysis of the aromatic amino acids proved the essential role of these residues in the active site for stabilization of the carbocation intermediates ${ }^{79,85}$. Positioning of GPP and FPP in the PamTps1 active site surrounded by these aromatic residues suggested that this docking analysis was rational and compatible with other crystal structures of terpene synthases.

Insights into the PamTps1 active site pocket. Not all terpene synthases have the ability to use multisubstrate. Steric limitations and configuration of the active site center and the overall protein stability contrib- 
A

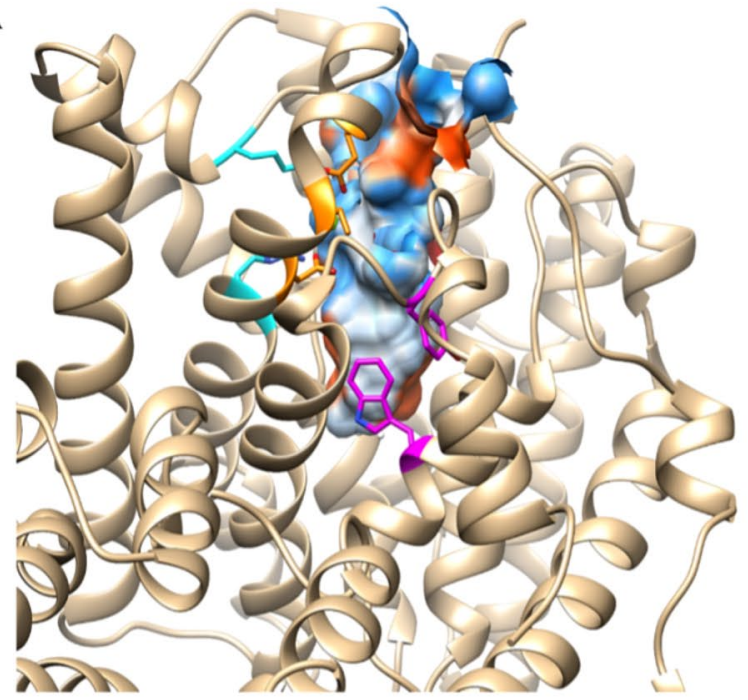

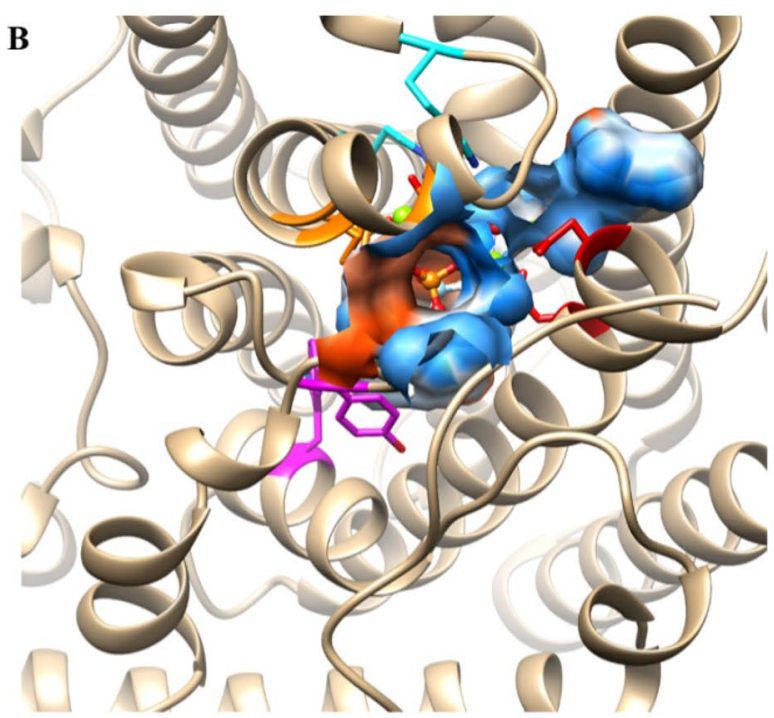

D

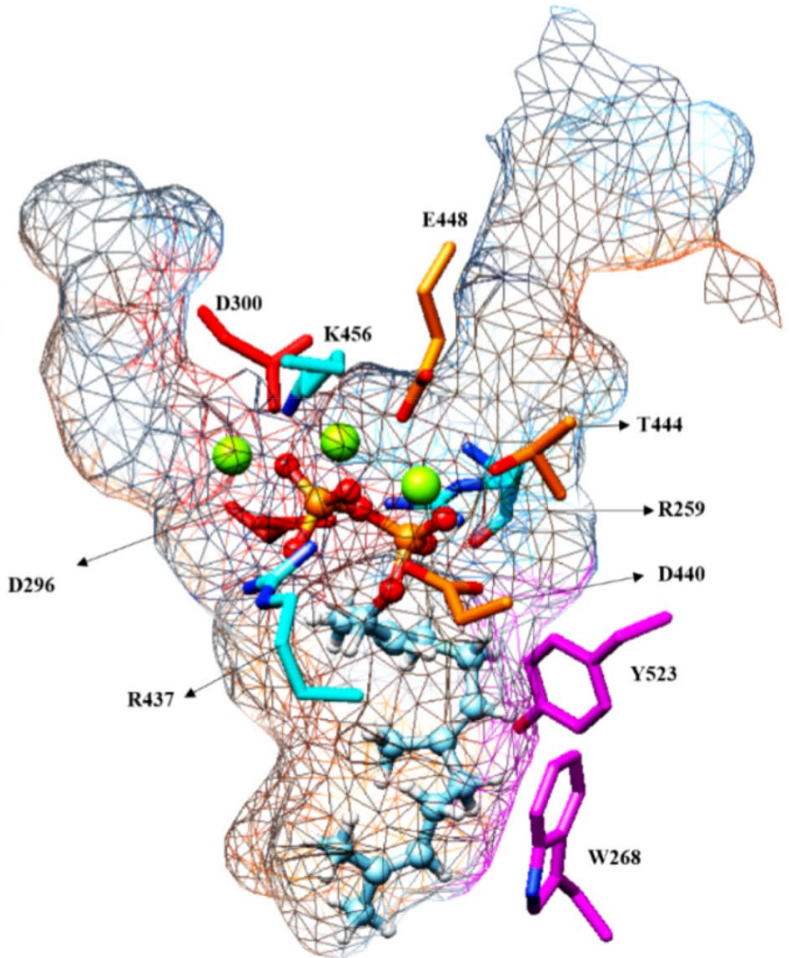

Figure 5. The PamTps1 active site pocket. The overview of PamTps1 active site pocket from (A) top and (B) side views. Docking positions of (C) GPP and (D) FPP in Pam Tps1 active site cavity. The Pam Tps1 active site is a deep hydrophobic pocket consisting of C, D, F, G, H and J helices. The red-orange ball and stick chains represent the PPi of substrate, green spheres are the $\mathrm{Mg}^{2+}$, the orange side chains are the DTE motifs, the blue side chains are the hydrogen bond donor residues and the magenta side chains represent the aromatic residues.

uted by the tertiary protein structure might rule out the use of multi-substrate ${ }^{12}$. The ability of terpene synthases to catalyze multiple substrates has been reported to be contributed by both size and residues of the active site pockets. In general, the active site pocket is slightly larger than the corresponding substrate and product, and size of the cavity is increasingly deeper and wider for increasingly longer chain products ${ }^{9,86}$. The active site of Streptomyces clavuligens linalool/nerolidol synthase (bLinS) has been shown to be large enough to accommodate sesquiterpene, which explained the fact that this enzyme recognized FPP as a substrate ${ }^{64}$. It was predicted that the active site pocket of PamTps1 was also large enough and unconstrained to accommodate FPP, resulting in nerolidol formation.

Using CASTp server and InterProScan analysis, the topographic features of the PamTps1 active site pocket containing the docked substrate was illustrated in Fig. 5 and amino acids that lined the pocket cavity were also identified (Table 3). Both substrates were appropriately docked in the PamTps1 active site cavity, thus enlightened 


\begin{tabular}{|c|c|c|}
\hline Structure/Motif & Residues & Functions \\
\hline N-terminal domain $\left(\mathrm{RRx}_{8} \mathrm{~W}\right)$ & R1R2S3G4N5Y6Q7P8SAW & Active site lid \\
\hline \multirow{2}{*}{ A-C loop (RxR) } & \multirow{2}{*}{ R259DR } & Active site lid \\
\hline & & R259-Hydrogen bond donor \\
\hline \multirow{3}{*}{ Helix C } & \multirow{3}{*}{ W268, Y272 } & Active site pocket \\
\hline & & W268-Aromatic residue surrounding non-polar hydrocarbon of substrate \\
\hline & & W268, Y272-Hydrophobic interaction with PPi \\
\hline \multirow{2}{*}{ Helix D1 } & \multirow{2}{*}{ I 288V289, L291V292T293 } & Active site pocket \\
\hline & & V289, V292T293-Hydrophobic interaction with PPi \\
\hline \multirow{2}{*}{ Helix D1(DDxxD) } & \multirow{2}{*}{ D296D297VY299D300 } & Active site pocket \\
\hline & & D296, D300-metal binding motif \\
\hline Helix F & F371, E374A375, Y378Y379 & Active site pocket \\
\hline Helix G1 & T396 & Active site pocket \\
\hline Turn & I397A398 & Active site pocket, hydrophobic interaction with PPi \\
\hline \multirow{2}{*}{ Helix G2 } & \multirow{2}{*}{ A399, A401A402 } & Active site pocket \\
\hline & & A399, A402-Hydrophobic interaction with PPi \\
\hline \multirow{5}{*}{ Helix H $(\mathrm{L}, \mathrm{V})(\mathrm{V}, \mathrm{L}, \mathrm{A})(\mathrm{N}, \mathrm{D}) \mathrm{D}(\mathrm{L}, \mathrm{I}, \mathrm{V}) \mathrm{x}(\mathrm{S}, \mathrm{T}) \mathrm{xxxE} / \mathrm{DTE}$} & \multirow{3}{*}{ L436R437L438AD440D441LG } & F447E448, E450- Active site lid \\
\hline & & Active site pocket \\
\hline & & R437-Hydrogen bond donor \\
\hline & \multirow{2}{*}{ T444APF447E448, E450 } & D440, T444, E448 - metal binding motif \\
\hline & & L436-Hydrophobic interaction with PPi \\
\hline \multirow{2}{*}{ H-al loop } & R451G452D453V454A455 & Active site lid \\
\hline & K456A457, V458 & K456-Hydrogen bond donor \\
\hline $3_{10}$ helix & Y517 & Active site pocket, hydrophobic interaction with PPi \\
\hline \multirow[b]{2}{*}{$\mathrm{J}-\mathrm{K}$ loop } & \multirow[b]{2}{*}{ G520D521G522Y523G524V525 } & Active site lid \\
\hline & & $\begin{array}{l}\text { Y523-Aromatic residue surrounding non-polar hydrocarbon of substrate/Hydrophobic } \\
\text { interaction with PPi }\end{array}$ \\
\hline
\end{tabular}

Table 3. Amino acid residues involved in the establishment of PamTps1 active site pocket and catalysis activity predicted using CASTp and InterProScan.

the multi-substrate use ability of PamTps1. The active site cavity of PamTps1 was a deep hydrophobic pocket with a contour defined by numerous aliphatic and aromatic side chains made of six helices of C, D, F, G, H and J (Table 3; Fig. 5) similarly as described for the BPPS structure ${ }^{5}$. Nine aromatic residues (W268, Y272, Y299, F371, Y378, Y379, F447, Y517 and Y523) outlined the hydrophobic walls of the active site cavity. This result was also supported by structural studies of other plant terpene synthases $5,9,25,72$. It was reported that arginine, phenylalanine, tyrosine, valine, tryptophan and isoleucine were the commonly observed amino acid residues at the catalytic site of the terpene synthases ${ }^{87}$, which was also observed in the PamTps1 active site. The presence of aromatic residue pairs (Y523 and W268) at the bottom of the active site did not appear to restrict the size of the active site, and the hydrocarbon group of FPP appeared to fit perfectly into the catalytic pocket, which may shed light on the possibility of PamTps1 accepting FPP as a substrate (Fig. 5). By analogy with the previous characterized enzymes, it was believed that the active site of PamTps1 was reasonably large and deep enough to accommodate both the GPP and FPP, resulting in the formation of linalool and nerolidol, respectively.

Residues from the $\mathrm{RRx}_{8} \mathrm{~W}$ motif, $\mathrm{RDR}$ motif, $\mathrm{H}-\alpha 1$ and J-K loops were observed to act as a catalytic lid that closed the active site entrance upon substrate binding (Table 3). Structural comparison with BPPS showed that the J-K loop of PamTps1 was longer than the equivalent loop in BPPS. Sugiura et al ${ }^{88}$ reported that the Backhousia citriodora linalool synthase had a long J-K loop and bulky amino acids around the active site that could partially inhibit water access to the active site, leading to the production of (-) linalool and minor amounts of myrcene and (-) limonene. Alignment of amino acids indicated that most Lamiaceae linalool synthases differed from other terpene synthases by a three-amino acid deletion at the --K loop region, thereby resulting in a more open structure, allowing easier access of water during substrate ionization ${ }^{25,89}$. However, no amino acid deletions at the J-K loop region were observed in the PamTps1 and it was assumed that the longer J-K loop could lead to the more open structure of the enzyme. The crystal structure of bLinS was also reported to be relatively open, allowing the carbocation intermediate to attack nearby water and led to linalool production ${ }^{64}$. Although the crystal structures PamTps1's open and closed active site conformations are not yet available, it is thought that PamTps1 does not undergo significant conformational changes between open and closed states, as observed with other linalool synthase $\mathrm{s}^{25,64}$. As a result, the active site was more susceptible to water access, resulting in the premature released of the carbocationic intermediates and the production of acyclic linalool and nerolidol ${ }^{25,64,89}$. Besides that, other conserved motifs considered to be part of the active site were LQLYEASFLL and GTLxEL ${ }^{63,66}$. However, there was no computational evidence that both motifs were involved in the formation of the PamTps 1 active site or in the catalysis reaction, as exhibited by the active site pocket analysis and protein docking studies. 


\section{Conclusion}

PamTps1 was classified as a linalool/nerolidol synthase with the ability to convert GPP and FPP into acyclic linalool and nerolidol, respectively. The catalytic activity of this recombinant synthase was optimal at $\mathrm{pH} 6.5$ and $30^{\circ} \mathrm{C}$ in the presence of $20 \mathrm{mM} \mathrm{Mg}^{2+}$ as a cofactor, which was within the range of most reported terpene synthases. PamTps1 catalysis was still stimulated by $\mathrm{Mn}^{2+}$ at the optimal concentration of $0.5 \mathrm{mM}$ in place of $\mathrm{Mg}^{2+}$, however the catalytic activity was decreased by 2.1 folds. The kinetic properties of PamTps 1 were analyzed using Michaelis-Menten equation, which revealed that it had a higher binding affinity and catalytic efficiency for GPP rather than FPP, as anticipated for a monoterpene synthase located in the plastid where the GPP pool was accessible. The Pam Tps1 model structure was successfully constructed from its amino acid sequences using BPPS as a template, and this model will serve as a first glimpse into the structural insights of Pam Tps1 catalytic site as a linalool/nerolidol synthase. The P. amboinicus linalool/nerolidol synthase exhibited features of a class I terpene synthase fold made up of $\alpha$-helices architecture that contain the $\mathrm{N}$-terminal domain and a catalytic C-terminal domain. Based on the prior knowledge of the reaction mechanisms of other monoterpene/sesquiterpene synthases, it is hypothesized that a PamTps1 reaction mechanism begins with the metal-dependent ionization of the PPi moiety of respective GPP or FPP to form a geranyl cation or farnesyl cation. Assisting the metal ions in PPi complexation are the basic residues of R259, R437 and K456 that direct the PPi away from the active site after ionization. The addition of water to the cationic intermediate, followed by deprotonation, resulted in the formation of acyclic terpenoids linalool and nerolidol. The ability of PamTps1 to use multiple substrates was believed to be due to the enzyme's active site that was large enough to accommodate larger substrate such as FPP, allowing water capture that caused premature termination and subsequent nerolidol formation. This model will serve as a framework for exploring the roles of active site residues in rational design to exchange the enzyme function between monoterpene and sesquiterpene synthase.

\section{Materials and methods}

Plant material. The leaves of $P$. amboinicus were collected from purchased plants which were maintained at the Faculty of Biotechnology and Biomolecular Sciences, Universiti Putra Malaysia in Selangor, Malaysia $\left(3^{\circ}\right.$ $00^{\prime} 26.4^{\prime \prime} \mathrm{N} 101^{\circ} 42^{\prime} 19.3^{\prime \prime}$ E). Plant authentication was performed by a botanist, Dr. Shamsul Khamis, from the School of Environmental Science and Natural Resources, Universiti Kebangsaan Malaysia, Selangor, Malaysia.

Functional characterization of recombinant PamTps1. The P. amboinicus linalool/nerolidol synthase (designated as PamTps1) (GenBank accession no: MK050501) was previously isolated and functionally characterized by Ashaari et al. ${ }^{15}$. Enzyme assay was conducted in a $100 \mu \mathrm{l}$ reaction containing assay buffer $(10 \mathrm{mM}$ Tris-HCl, pH 7.5, 10\% (v/v) glycerol, 1 mM DTT, $0.1 \mathrm{mM} \mathrm{NaWO}_{4}, 0.05 \mathrm{mM} \mathrm{NaF}$ ), $10 \mathrm{mM} \mathrm{MgCl}_{2}$ and 3-5 $\mu \mathrm{g}$ of purified protein. The enzymatic reaction was initiated by addition of $27 \mu \mathrm{M}$ of GPP or FPP (Sigma Aldrich, USA) and incubated at $30^{\circ} \mathrm{C}$ for $30 \mathrm{~min}$. The terpene products released into the headspace of the assay mixture were collected by solid phase micro extraction (SPME) with a $100 \mu \mathrm{m}$ polydimethylsiloxane (PDMS) coated fiber (Supelco, USA) at $60{ }^{\circ} \mathrm{C}$ for $30 \mathrm{~min}$. The adsorbed products were separated through Agilent HP-5MS column $(30 \mathrm{~m} \times 250 \mu \mathrm{m}$ inner diameter $\times 0.25 \mu \mathrm{m}$ film thickness $)$ and analyzed using Agilent 7890A gas chromatograph equipped with Agilent 5975C quadrupole mass spectrometer (Agilent Technologies, Santa Clara, USA). The SPME fiber containing the volatile compounds was inserted into GC injection port and thermally desorbed at $250{ }^{\circ} \mathrm{C}$ for $15 \mathrm{~min}$ using splitless mode with helium as carrier gas at a flow rate of $1 \mathrm{ml} / \mathrm{min}$. The oven temperature was initially maintained at $50^{\circ} \mathrm{C}$ and gradually increased to $280^{\circ} \mathrm{C}$ at a rate of $10^{\circ} \mathrm{C} / \mathrm{min}$ for $3 \mathrm{~min}$. The temperature of the ion source and transfer line was set at $220^{\circ} \mathrm{C}$ and $280^{\circ} \mathrm{C}$, respectively, and electron impact mass spectra was recorded at $70 \mathrm{eV}$ ionization energy. All assay products were identified by comparison of the mass spectra to the NIST14 library database and by comparing the retention times and mass spectra to the authentic standards of (-) linalool and nerolidol (Sigma Aldrich, USA). Standard calibration curves were constructed using the pure standards with concentrations ranging from 10 to $1000 \mu \mathrm{g} / \mathrm{ml}$ in the same conditions as the assay reactions.

Optimum temperature and $\mathrm{pH}$ of $\mathrm{PamTps} 1$ were determined by assaying at various temperatures ranging from 25 to $37^{\circ} \mathrm{C}$ and seven $\mathrm{pH}$ levels, respectively. The buffer systems used in this study were 2-(N-Morpholino) ethanesulfonic acid (MES) buffer ( $\mathrm{pH}$ 5.5-6.5) and Tris- $\mathrm{HCl}$ buffer ( $\mathrm{pH}$ 7.0-9.0). Divalent cation preferences and optimum concentrations were determined by assaying at different $\mathrm{MgCl}_{2}(0.0,2.0,4.0,10.0,20.0,50.0,100$, $250 \mathrm{mM})$ and $\mathrm{MnCl}_{2}(0.0,0.1,0.2,1.0,5.0,10.0 \mathrm{mM})$ concentrations. The substrate dependence of PamTps1 was studied by adding GPP or FPP with different concentrations ranging from 0 to $200 \mu \mathrm{M}$ to the reaction mixture. The kinetic parameters $K_{\mathrm{m}}, V_{\text {max }}, k_{\text {cat }}$ and $k_{\text {cat }} / V_{\max }$ values were determined by fitting the data to the Michaelis-Menten equation analyzed using GraphPad Prism8. Extracted total crude proteins from Rosetta 2 (DE3) E. coli cells carrying empty pET-32b $(+)$ vector were used as a negative control in place of Pam Tps1. One unit (U) of activity was defined as the amount of enzyme required to produce $1 \mu$ mole enzymatic product per min per ml under standard conditions. Specific activity was defined as enzyme activity (U) per mg of protein.

Secondary structure and 3D structure prediction. The motifs and domains were identified using MOTIFinder Search (https://www.genome.jp/tools/motif/), SMART (Simple Modular Architecture Research Tool) (http://smart.embl-heidelberg.de/) and InterProScan ${ }^{90}$. Secondary structure and domain boundary were predicted using PSIPRED Protein Structure Prediction (PSIPRED v3.3) ${ }^{56}$ (http://bioinf.cs.ucl.ac.uk/psipred/) and Protein Domain Prediction (DomPred) ${ }^{91}$ (http://bioinf.cs.ucl.ac.uk/psipred/?dompred), respectively. The three-dimensional protein structure of PamTps1 model was constructed from the amino acid sequence using automated comparative protein modelling server SWISS-MODEL ${ }^{92}$ (https://swissmodel.expasy.org/) and visualized using UCSF Chimera v $1.13 \mathrm{rc}^{93}$. The template for building the 3D structure of PamTps1 was obtained 
from the SWISS-MODEL Template Library and the most homologous sequence was considered as a potential template for the homology modeling ${ }^{92}$. The structural superimposition and calculation of the root-mean-square deviations (RMSD) between the model and template were conducted via Chimera using the carbon alpha (Ca) fitting method.

Validation of the PamTps1 model. The 3D model was evaluated by SWISS-MODEL's Global Model Quality Estimation (GMQE) and Qualitative Model Energy Analysis (QMEAN) function. Structural evaluation and stereochemical analysis was conducted with Ramachandran plot using RAMPAGE server ${ }^{44}$ (http://mordr ed.bioc.cam.ac.uk/ rapper/rampage.php). The model was further subjected to the Structural Analysis and Verification Server v. 5.0 (SAVES) (http://servicesn.mbi.ucla.edu/SAVES/) which included PROCHECK ${ }^{95}$, PROVE (PROtein Volume Evaluation) ${ }^{96}$, ERRAT ${ }^{97}$ and Verify3D analysis ${ }^{98,99}$ to evaluate the reliability of the predicted protein structure. Problematic region of the model was identified using Protein Structure Analysis (ProSA) server (https://prosa.services.came.sbg.ac.at), a tool commonly used to check 3D model protein structures for potential errors $^{100}$.

Molecular docking. Protein-ligand docking simulation was conducted using the SwissDock server ${ }^{101}$ with the ligand selected from the ZINC database ${ }^{102}$. The docking assays were run using default parameters and the results were viewed via the Chimera software. Hydrogen bond network and distance between ligand and active site residues were also analyzed using Chimera. Distances of the amino acid residues which interacted with $\mathrm{Mg}^{2+}$ were also calculated. Identification of amino acids surrounding the active site was conducted by searching for atoms within $<5 \AA$ of the docked ligand. Validation of metal-binding site was conducted using CheckMyMetal server $^{74}$ (https://cmm.minorlab.org/) to assess the geometry of the metal-binding site and the vacancy of the metal.

Active site pocket analysis. Predictions of the active site pocket and of the amino acid(s) that contributed to the pocket were conducted by applying the CASTp 3.0 server (Computed Atlas of Surface Topography of Proteins) ${ }^{103}$.

Ethical statement of research involving plants. The $P$. amboinicus that was used in this study was purchased from Petani Kota Nursery located at Dengkil, Selangor, Malaysia ( $2^{\circ} 53^{\prime} 38.7^{\prime \prime} \mathrm{N} 101^{\circ} 45^{\prime} 9.0^{\prime \prime} \mathrm{E}$ ), and it is from cultivated origin. All the methodology and data collection comply with relevant institutional, national and international guidelines and legislation.

\section{Data availability}

Data deposition: the sequences reported in this paper have been deposited in the GenBank database (GenBank Accession No. MK050501).

Received: 22 March 2021; Accepted: 11 August 2021

Published online: 24 August 2021

\section{References}

1. Tholl, D. Biosynthesis and biological functions of terpenoids in plants in Biotechnology of isoprenoids (eds. Schrader, J. \& Bohlmann, J.) 63-106 (Springer, 2015).

2. George, K. W., Alonso-Gutierrez, J., Keasling, J. D. \& Lee, T. S. Isoprenoid drugs, biofuels, and chemicals-artemisinin, farnesene, and beyond in Biotechnology of isoprenoids (eds. Schrader, J. \& Bohlmann, J.) 355-389 (Springer, 2015).

3. Turner, G., Gershenzon, J., Nielson, E. E., Froehlich, J. E. \& Croteau, R. Limonene synthase, the enzyme responsible for monoterpene biosynthesis in peppermint, is localized to leucoplasts of oil gland secretory cells. Plant Physiol. 120, 879-886 (1999).

4. Bohlmann, J., Meyer-Gauen, G. \& Croteau, R. Plant terpenoid synthases: Molecular biology and phylogenetic analysis. Proc. Natl. Acad. Sci. 95, 4126-4133 (1998).

5. Whittington, D. A. et al. Bornyl diphosphate synthase: Structure and strategy for carbocation manipulation by a terpenoid cyclase. Proc. Natl. Acad. Sci. 99, 15375-15380 (2002).

6. Hyatt, D. C. et al. Structure of limonene synthase, a simple model for terpenoid cyclase catalysis. Proc. Natl. Acad. Sci. 104, 5360-5365 (2007)

7. Degenhardt, J., Köllner, T. G. \& Gershenzon, J. Monoterpene and sesquiterpene synthases and the origin of terpene skeletal diversity in plants. Phytochemistry 70, 1621-1637 (2009).

8. Christianson, D. W. Structural and chemical biology of terpenoid cyclases. Chem. Rev. 117, 11570-11648 (2017).

9. Köksal, M., Jin, Y., Coates, R. M., Croteau, R. \& Christianson, D. W. Taxadiene synthase structure and evolution of modular architecture in terpene biosynthesis. Nature 469, 116-120 (2011).

10. Crocoll, C., Asbach, J., Novak, J., Gershenzon, J. \& Degenhardt, J. Terpene synthases of oregano (Origanum vulgare L.) and their roles in the pathway and regulation of terpene biosynthesis. Plant Mol. Biol. 73, 587-603 (2010).

11. Lima, A. S. et al. Genomic characterization, molecular cloning and expression analysis of two terpene synthases from Thymus caespititius (Lamiaceae). Planta 238, 191-204 (2013).

12. Pazouki, L. \& Niinemets, Ü. Multi-substrate terpene synthases: Their occurrence and physiological significance. Front. Plant Sci. 7, 1019 (2016).

13. Nagegowda, D. A., Gutensohn, M., Wilkerson, C. G. \& Dudareva, N. Two nearly identical terpene synthases catalyze the formation of nerolidol and linalool in snapdragon flowers. Plant J. 55, 224-239 (2008).

14. Magnard, J.-L. et al. Linalool and linalool nerolidol synthases in roses, several genes for little scent. Plant Physiol. Biochem. 127, 74-87 (2018).

15. Ashaari, N. S. et al. Functional characterization of a new terpene synthase from Plectranthus amboinicus. PLoS ONE 15, e0235416 (2020).

16. Li, R. et al. Reprogramming the chemodiversity of terpenoid cyclization by remolding the active site contour of epi-isozizaene synthase. Biochemistry 53, 1155-1168 (2014). 
17. Aaron, J. A. \& Christianson, D. W. Trinuclear metal clusters in catalysis by terpenoid synthases. Pure Appl. Chem. 82, 1585-1597 (2010).

18. Christianson, D. W. Unearthing the roots of the terpenome. Curr. Opin. Chem. Biol. 12, 141-150 (2008).

19. Raguso, R. A. More lessons from linalool: Insights gained from a ubiquitous floral volatile. Curr. Opin. Plant Biol. 32, 31-36 (2016).

20. Kamatou, G. P. P. \& Viljoen, A. M. Linalool-A review of a biologically active compound of commercial importance. Nat. Prod. Commun. 3, 1183-1192 (2018).

21. Chen, S. et al. (E)-Nerolidol is a volatile signal that induces defenses against insects and pathogens in tea plants. Hortic. Res. 7, $52(2020)$.

22. Chan, W.-K., Tan, L., Chan, K.-G., Lee, L.-H. \& Goh, B.-H. Nerolidol: A sesquiterpene alcohol with multi-faceted pharmacological and biological activities. Molecules 21, 529 (2016).

23. Yue, Y., Yu, R. \& Fan, Y. Characterization of two monoterpene synthases involved in floral scent formation in Hedychium coronarium. Planta 240, 745-762 (2014).

24. Martin, D. M. et al. Functional annotation, genome organization and phylogeny of the grapevine (Vitis vinifera) terpene synthase gene family based on genome assembly, FLcDNA cloning, and enzyme assays. BMC Plant Biol. 10, 226 (2010).

25. Crowell, A. L., Williams, D. C., Davis, E. M., Wildung, M. R. \& Croteau, R. Molecular cloning and characterization of a new linalool synthase. Arch. Biochem. Biophys. 405, 112-121 (2002).

26. Abbas, F., Ke, Y., Yu, R. \& Fan, Y. Functional characterization and expression analysis of two terpene synthases involved in floral scent formation in Lilium 'Siberia'. Planta 249, 71-93 (2019).

27. Chen, X. et al. Characterisation of an (S)-linalool synthase from kiwifruit (Actinidia arguta) that catalyses the first committed step in the production of floral lilac compounds. Funct. Plant Biol. 37, 232 (2010).

28. Landmann, C. et al. Cloning and functional characterization of three terpene synthases from lavender (Lavandula angustifolia). Arch. Biochem. Biophys. 465, 417-429 (2007).

29. Pichersky, E., Lewinsohn, E. \& Croteau, R. Purification and characterization of S-linalool synthase and enzyme involved in the production of floral scent in Clarkia breweri. Arch. Biochem. Biophys. 316, 803-807 (1995).

30. Yeom, S.-J. et al. Molecular and biochemical characterization of a novel isoprene synthase from Metrosideros polymorpha. BMC Plant Biol. 18, 118 (2018).

31. Niinemets, Ü., Seufert, G., Steinbrecher, R. \& Tenhunen, J. D. A model coupling foliar monoterpene emissions to leaf photosynthetic characteristics in Mediterranean evergreen Quercus species. New Phytol. 153, 257-275 (2002).

32. Fischbach, R. J., Zimmer, I., Steinbrecher, R., Pfichner, A. \& Schnitzler, J. P. Monoterpene synthase activities in leaves of Picea abies (L.) Karst. and Quercus ilex L. Phytochemistry 54, 257-265 (2000).

33. Davis, E. M. \& Croteau, R. Cyclization enzymes in the biosynthesis of monoterpenes, sesquiterpenes, and diterpenes in Biosynthesis. Topics in current chemistry (eds. Leeper, F. J. \& Vederas, J. C.) 53-95 (Springer, 2000).

34. Galata, M., Sarker, L. S. \& Mahmoud, S. S. Transcriptome profiling, and cloning and characterization of the main monoterpene synthases of Coriandrum sativum L. Phytochemistry 102, 64-73 (2014).

35. Demissie, Z. A. et al. Cloning, functional characterization and genomic organization of 1,8-cineole synthases from Lavandula. Plant Mol. Biol. 79, 393-411 (2012).

36. Ker, D.-S. et al. Purification and biochemical characterization of recombinant Persicaria minor $\beta$-sesquiphellandrene synthase. PeerJ 5, e2961 (2017).

37. Bisswanger, H. Enzyme assays. Perspect. Sci. 1, 41-55 (2014).

38. Cane, D. E., Xue, Q. \& Fitzsimons, B. C. Trichodiene synthase. Probing the role of the highly conserved aspartate-rich region by site-directed mutagenesis. Biochemistry 35, 12369-12376 (1996).

39. Fujita, Y. et al. Biosynthesis of volatile terpenes that accumulate in the secretory cavities of young leaves of Japanese pepper (Zanthoxylum piperitum): Isolation and functional characterization of monoterpene and sesquiterpene synthase genes. Plant Biotechnol. 34, 17-28 (2017).

40. Morehouse, B. R. et al. Functional and structural characterization of a (+)-limonene synthase from Citrus sinensis. Biochemistry 56, 1706-1715 (2017).

41. Ruan, J.-X. et al. Isolation and characterization of three new monoterpene synthases from Artemisia annua. Front. Plant Sci. 7, $1-10(2016)$

42. Zhang, X. et al. Identification and functional characterization of three new terpene synthase genes involved in chemical defense and abiotic stresses in Santalum album. BMC Plant Biol. 19, 1-18 (2019).

43. Nieuwenhuizen, N. J. et al. Natural variation in monoterpene synthesis in kiwifruit: Transcriptional regulation of terpene synthases by NAC and ETHYLENE-INSENSITIVE3-like transcription factors. Plant Physiol. 167, 1243-1258 (2015).

44. Iijima, Y., Gang, D. R., Fridman, E., Lewinsohn, E. \& Pichersky, E. Characterization of geraniol synthase from the peltate glands of sweet basil. Plant Physiol. 134, 370-379 (2004).

45. Schnee, C., Köllner, T. G., Gershenzon, J. \& Degenhardt, J. The maize gene terpene synthase 1 encodes a sesquiterpene synthase catalyzing the formation of (E)- $\beta$-farnesene, (E)-nerolidol, and (E, E)-farnesol after herbivore damage. Plant Physiol. 130, 2049-2060 (2002).

46. Jia, J. W., Crock, J., Lu, S., Croteau, R. \& Chen, X. Y. (3R)-Linalool synthase from Artemisia annua L.: cDNA isolation, characterization, and wound induction. Arch. Biochem. Biophys. 372, 143-149 (1999).

47. Alonso, W. R. \& Croteau, R. Purification and characterization of the monoterpene cyclase $\gamma$-terpinene synthase from Thymus vulgaris. Arch. Biochem. Biophys. 286, 511-517 (1991).

48. Köllner, T. G., Schnee, C., Gershenzon, J. \& Degenhardt, J. The variability of sesquiterpenes emitted from two Zea mays cultivars is controlled by allelic variation of two terpene synthase genes encoding stereoselective multiple product enzymes. Plant Cell 16, 1115-1131 (2004)

49. Marschner, H. Functions of mineral nutrients: Micronutrients in Mineral nutrition of higher plants (ed. Marschner, H.) 313-404 (Elsevier, 1995).

50. Lin, Y. L., Lee, Y. R., Huang, W. K., Chang, S. T. \& Chu, F. H. Characterization of S-(+)-linalool synthase from several provenances of Cinnamomum osmophloeum. Tree Genet. Genomes 10, 75-86 (2014).

51. Green, S. A. et al. Identification, functional characterization, and regulation of the enzyme responsible for floral (E)-nerolidol biosynthesis in kiwifruit (Actinidia chinensis). J. Exp. Bot. 63, 1951-1967 (2012).

52. Cane, D. E. Isoprenoid biosynthesis: Overview in Comprehensive natural products chemistry (eds. Barton, D., Nakanishi, K. \& Meth-Cohn, O.) 1-13 (Elsevier, 1999).

53. Wise, M. L. \& Croteau, R. Monoterpene biosynthesis in Comprehensive natural products chemistry (eds. Barton, D., Nakanishi, K. \& Meth-Cohn, O.) 97-153 (Elsevier, 1999).

54. Bar-Even, A. et al. The moderately efficient enzyme: Evolutionary and physicochemical trends shaping enzyme parameters. Biochemistry 50, 4402-4410 (2011).

55. Gao, F. et al. Identification and characterization of terpene synthase genes accounting for volatile terpene emissions in flowers of Freesia x hybrida. J. Exp. Bot. 69, 4249-4265 (2018).

56. Buchan, D. W. A., Minneci, F., Nugent, T. C. O., Bryson, K. \& Jones, D. T. Scalable web services for the PSIPRED Protein Analysis Workbench. Nucleic Acids Res. 41, W349-W357 (2013). 
57. Letunic, I. \& Bork, P. 20 years of the SMART protein domain annotation resource. Nucleic Acids Res. 46, D493-D496 (2018).

58. Dudareva, N., Cseke, L., Blanc, V. M. \& Pichersky, E. Evolution of floral scent in Clarkia: novel patterns of S-linalool synthase gene expression in the C. breweri flower. Plant Cell 8, 1137-1148 (1996).

59. González, V., Grundy, D. J., Faraldos, J. A. \& Allemann, R. K. The amino-terminal segment in the $\beta$-domain of $\delta$-cadinene synthase is essential for catalysis. Org. Biomol. Chem. 14, 7451-7454 (2016).

60. Zhou, K. et al. Insights into diterpene cyclization from structure of bifunctional abietadiene synthase from Abies grandis. J. Biol. Chem. 287, 6840-6850 (2012).

61. Williams, D. C., McGarvey, D. J., Katahira, E. J. \& Croteau, R. Truncation of limonene synthase preprotein provides a fully active 'pseudomature' form of this monoterpene cyclase and reveals the function of the amino-terminal arginine pair. Biochemistry 37, 12213-12220 (1998).

62. Mcgeady, P. \& Croteau, R. Isolation and characterization of an active-site peptide from a monoterpene cyclase labeled with a mechanism-based inhibitor. Arch. Biochem. Biophys. 317, 149-155 (1995).

63. Wise, M. L., Savage, T. J., Katahira, E. \& Croteau, R. Monoterpene synthases from common sage (Salvia officinalis): cDNA isolation, characterization, and functional expression of $(+)$-sabinene synthase, 1,8-cineole synthase, and (+)-bornyl diphosphate synthase. J. Biol. Chem. 273, 14891-14899 (1998).

64. Karuppiah, V. et al. Structural basis of catalysis in the bacterial monoterpene synthases linalool synthase and 1,8-cineole synthase. ACS Catal. 7, 6268-6282 (2017).

65. Kampranis, S. C. et al. Rational conversion of substrate and product specificity in a Salvia monoterpene synthase: Structural insights into the evolution of terpene synthase function. Plant Cell 19, 1994-2005 (2007).

66. Li, R. \& Fan, Y. Molecular cloning and expression analysis of a terpene synthase gene, HcTPS2, in Hedychium coronarium. Plant Mol. Biol. Rep. 29, 35-42 (2011).

67. Tarshis, L. C., Yan, M., Poulter, C. D. \& Sacchettini, J. C. Crystal structure of recombinant farnesyl diphosphate synthase at 2.6-A resolution. Biochemistry 33, 10871-10877 (1994).

68. Biasini, M. et al. SWISS-MODEL: Modelling protein tertiary and quaternary structure using evolutionary information. Nucleic Acids Res. 42, 252-258 (2014).

69. Benkert, P., Biasini, M. \& Schwede, T. Toward the estimation of the absolute quality of individual protein structure models. Bioinformatics 27, 343-350 (2011).

70. Wang, J. \& Eck, M. J. Protein architecture: Relationship of form and function in Hematology (eds. Hoffman, R. et al) 59-67 (Elsevier, 2018).

71. Rynkiewicz, M. J., Cane, D. E. \& Christianson, D. W. Structure of trichodiene synthase from Fusarium sporotrichioides provides mechanistic inferences on the terpene cyclization cascade. Proc. Natl. Acad. Sci. 98, 13543-13548 (2001).

72. Starks, C. M. Structural basis for cyclic terpene biosynthesis by tobacco 5-epi-aristolochene synthase. Science 277, 1815-1820 (1997).

73. Köksal, M., Zimmer, I., Schnitzler, J. P. \& Christianson, D. W. Structure of isoprene synthase illuminates the chemical mechanism of teragram atmospheric carbon emission. J. Mol. Biol. 402, 363-373 (2010).

74. Zheng, H. et al. CheckMyMetal: A macromolecular metal-binding validation tool. Acta Crystallogr. Sect. D Struct. Biol. 73, 223-233 (2017)

75. Zheng, H. et al. Validation of metal-binding sites in macromolecular structures with the CheckMyMetal web server. Nat. Protoc. 9, 156-170 (2014)

76. Brandt, W. et al. Molecular and structural basis of metabolic diversity mediated by prenyldiphosphate converting enzymes. Phytochemistry 70, 1758-1775 (2009).

77. Yahyaa, M. et al. Identification, functional characterization, and evolution of terpene synthases from a basal dicot. Plant Physiol. 169, 1683-1697 (2015).

78. Abdallah, I. I. \& Quax, W. J. A glimpse into the biosynthesis of terpenoids. KnE Life Sci. 3, 81-98 (2017).

79. Abdallah, I. I., Van Merkerk, R., Klumpenaar, E. \& Quax, W. J. Catalysis of amorpha-4,11-diene synthase unraveled and improved by mutability landscape guided engineering. Sci. Rep. 8, 1-11 (2018).

80. Hosfield, D. J. et al. Structural basis for bisphosphonate-mediated inhibition of isoprenoid biosynthesis. J. Biol. Chem. 279, 8526-8529 (2004).

81. Huang, H. et al. Structure of a membrane-embedded prenyltransferase homologous to UBIAD1. PLoS Biol. 12, 1-11 (2014).

82. McAndrew, R. P. et al. Structure of a three-domain sesquiterpene synthase: A prospective target for advanced biofuels production. Structure 19, 1876-1884 (2011)

83. Srividya, N., Davis, E. M., Croteau, R. B. \& Lange, B. M. Functional analysis of (4S)-limonene synthase mutants reveals determinants of catalytic outcome in a model monoterpene synthase. Proc. Natl. Acad. Sci. 112, 3332-3337 (2015).

84. Abdallah, I. I., Czepnik, M., van Merkerk, R. \& Quax, W. J. Insights into the three-dimensional structure of amorpha-4,11-diene synthase and probing of plasticity residues. J. Nat. Prod. 79, 2455-2463 (2016).

85. Zhang, F., Chen, N. \& Wu, R. Molecular dynamics simulations elucidate conformational dynamics responsible for the cyclization reaction in TEAS. J. Chem. Inf. Model. 56, 877-885 (2016).

86. Chang, T. H., Guo, R. T., Ko, T. P., Wang, A. H. J. \& Liang, P. H. Crystal structure of type-III geranylgeranyl pyrophosphate synthase from Saccharomyces cerevisiae and the mechanism of product chain length determination. J. Biol. Chem. 281, 14991-15000 (2006).

87. Kumari, I., Ahmed, M. \& Akhter, Y. Evolution of catalytic microenvironment governs substrate and product diversity in trichodiene synthase and other terpene fold enzymes. Biochimie 144, 9-20 (2018).

88. Sugiura, M. et al. Molecular cloning and characterization of a linalool synthase from lemon myrtle. Biosci. Biotechnol. Biochem. 75, 1245-1248 (2011).

89. van Schie, C. C. N., Haring, M. A. \& Schuurink, R. C. Tomato linalool synthase is induced in trichomes by jasmonic acid. Plant Mol. Biol. 64, 251-263 (2007).

90. Mitchell, A. L. et al. InterPro in 2019: Improving coverage, classification and access to protein sequence annotations. Nucleic Acids Res. 47, D351-D360 (2019).

91. Bryson, K., Cozzetto, D. \& Jones, D. T. Computer-assisted protein domain boundary prediction using the DomPred server. Curr. Protein Pept. Sci. 8, 181-188 (2007).

92. Waterhouse, A. et al. SWISS-MODEL: Homology modelling of protein structures and complexes. Nucleic Acids Res. 46, W296W303 (2018).

93. Pettersen, E. F. et al. UCSF Chimera-A visualization system for exploratory research and analysis. J. Comput. Chem. 25, 1605-1612 (2004).

94. Lovell, S. C. et al. Structure validation by C $\alpha$ geometry: $\phi$, $\psi$ and C $\beta$ deviation. Proteins Struct. Funct. Genet. 50, 437-450 (2003).

95. Laskowski, R. A., MacArthur, M. W., Moss, D. S. \& Thornton, J. M. PROCHECK: A program to check the stereochemical quality of protein structures. J. Appl. Crystallogr. 26, 283-291 (1993).

96. Pontius, J., Richelle, J. \& Wodak, S. J. Deviations from standard atomic volumes as a quality measure for protein crystal structures. J. Mol. Biol. 264, 121-136 (1996).

97. Colovos, C. \& Yeates, T. O. Verification of protein structures: Patterns of nonbonded atomic interactions. Protein Sci. 2, 15111519 (1993). 
98. Lüthy, R., Bowie, J. U. \& Eisenberg, D. Assessment of protein models with three-dimensional profiles. Nature 356, 83-85 (1992).

99. Eisenberg, D., Lüthy, R. \& Bowie, J. U. VERIFY3D: Assessment of protein models with three-dimensional profiles. Methods Enzymol. 277, 396-404 (1997).

100. Wiederstein, M. \& Sippl, M. J. ProSA-web: Interactive web service for the recognition of errors in three-dimensional structures of proteins. Nucleic Acids Res. 35, 407-410 (2007).

101. Grosdidier, A., Zoete, V. \& Michielin, O. SwissDock, a protein-small molecule docking web service based on EADock DSS. Nucleic Acids Res. 39, 270-277 (2011).

102. Sterling, T. \& Irwin, J. J. ZINC 15-Ligand discovery for everyone. J. Chem. Inf. Model. 55, 2324-2337 (2015).

103. Tian, W., Chen, C., Lei, X., Zhao, J. \& Liang, J. CASTp 3.0: Computed atlas of surface topography of proteins. Nucleic Acids Res. 46, 363-367 (2018).

\section{Acknowledgements}

We thank Professor Jacqueline Batley from University of Western Australia, Dr. Tan Soon Guan (Professor of Genetics, Universiti Putra Malaysia) and Dr. Adam Leow Thean Chor (Department of Cell \& Molecular Biology, Faculty of Biotechnology \& Biomolecular Sciences, Universiti Putra Malaysia) for their critical comments on our manuscript.

\section{Author contributions}

N.S.A. participated in designing and carrying out the experiments, analyzing the data and writing the manuscript; M.H.A.R., S.S., K.S.L., A.A.L.S., R.A.R. and J.O.A. involved in funding acquisition and supervision. All authors reviewed the manuscript.

\section{Funding}

This research work was supported by the MOSTI Fundamental Research Grant Scheme FRGS/2/2014/STWN10/ UPM/02/1 and by the UPM Putra Grant GP-IPS/2015/9463800.

\section{Competing interests}

The authors declare no competing interests.

\section{Additional information}

Supplementary Information The online version contains supplementary material available at https://doi.org/ 10.1038/s41598-021-96524-z.

Correspondence and requests for materials should be addressed to J.O.A.

Reprints and permissions information is available at www.nature.com/reprints.

Publisher's note Springer Nature remains neutral with regard to jurisdictional claims in published maps and institutional affiliations.

(c) (i) Open Access This article is licensed under a Creative Commons Attribution 4.0 International cc) License, which permits use, sharing, adaptation, distribution and reproduction in any medium or format, as long as you give appropriate credit to the original author(s) and the source, provide a link to the Creative Commons licence, and indicate if changes were made. The images or other third party material in this article are included in the article's Creative Commons licence, unless indicated otherwise in a credit line to the material. If material is not included in the article's Creative Commons licence and your intended use is not permitted by statutory regulation or exceeds the permitted use, you will need to obtain permission directly from the copyright holder. To view a copy of this licence, visit http://creativecommons.org/licenses/by/4.0/.

(C) The Author(s) 2021 